\title{
Type A GABA-Receptor-Dependent Synaptic Transmission Sculpts Dendritic Arbor Structure in Xenopus Tadpoles In Vivo
}

\author{
Wanhua Shen, ${ }^{1,2 *}$ Jorge Santos Da Silva, ${ }^{1 *}$ Haiyan He, ${ }^{1,2}$ and Hollis T. Cline ${ }^{1,2}$ \\ ${ }^{1}$ Cold Spring Harbor Laboratory, Cold Spring Harbor, New York 11724, and ${ }^{2}$ The Scripps Research Institute, La Jolla, California 92037
}

\begin{abstract}
The emergence of dendritic arbor structure in vivo depends on synaptic inputs. We tested whether inhibitory GABAergic synaptic transmission regulates Xenopus optic tectal cell dendritic arbor development in vivo by expressing a peptide corresponding to an intracellular loop (ICL) of the $\gamma 2$ subunit of type A GABA receptors $\left(G_{A B A} R\right)$, which is required to anchor $G_{A B A_{A}}$ receptors to the postsynaptic scaffold. Enhanced green fluorescent protein (EGFP)-tagged ICL (EGFP-ICL) was distributed in a punctate pattern at putative inhibitory synapses, identified by vesicular GABA transporter immunoreactive puncta. ICL expression completely blocked $\mathrm{GABA}_{\mathrm{A}} \mathrm{R}$-mediated transmission in $36 \%$ of transfected neurons and significantly reduced $\mathrm{GABA}_{\mathrm{A}} \mathrm{R}$-mediated synaptic currents relative to AMPA receptor-mediated synaptic currents in the remaining transfected neurons without altering release probability or neuronal excitability. Further analysis of ICL-expressing neurons with residual $\mathrm{GABA}_{\mathrm{A}} \mathrm{R}$-mediated inputs showed that the capacity of benzodiazepine to enhance GABAergic synaptic responses was reduced in ICL-expressing neurons, indicating that they were likely depleted of $\gamma 2$ subunit-containing $\mathrm{GABA}_{\mathrm{A}} \mathrm{R}$. Neurons expressing a mutant form of ICL were comparable to controls. In vivo time-lapse images showed that ICL-expressing neurons have more sparsely branched dendritic arbors, which expand over larger neuropil areas than EGFPexpressing control neurons. Analysis of branch dynamics indicated that ICL expression affected arbor growth by reducing rates of branch addition. Furthermore, we found that decreasing GABAergic synaptic transmission with ICL expression blocked visual experience dependent dendritic arbor structural plasticity. Our findings establish an essential role for inhibitory GABAergic synaptic transmission in the regulation of dendritic structural plasticity in Xenopus in vivo.
\end{abstract}

\section{Introduction}

Dendrite structure determines the spatial extent and types of afferent input a neuron receives as well as the biophysical properties of the dendritic arbor (Cline, 2001; Wong and Ghosh, 2002). Establishment of dendritic arbor structure in vivo depends on both excitatory and inhibitory input activity (Sanes and Hafidi, 1996; Cline, 2001); however, the role of inhibitory GABAergic synaptic transmission in regulating dendritic arbor development remains unclear, likely because GABA can act as a depolarizing or hyperpolarizing transmitter depending on the expression of chloride transporters and therefore internal chloride concentration in the postsynaptic neuron. Activation of ionotropic type A GABA receptors $\left(G_{A B A} R\right)$ in young neurons increases process outgrowth and synaptogenesis, likely mediated by GABAinduced excitation (Barbin et al., 1993; Ben-Ari, 2002; Cancedda et al., 2007). Blocking inhibitory GABAergic transmission in

\footnotetext{
Received Nov. 5, 2008; revised Feb. 12, 2009; accepted March 12, 2009.

This work was supported by the National Eye Institute (Grant EY011261; H.T.C.). We thank Simon Rumpel for

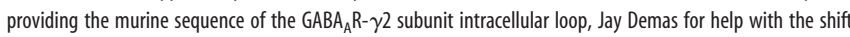
analysis, and the members of the Cline laboratory for discussion and comments. J.S.S. was supported by the European Molecular Biology Organization and the Human Frontier Science Program.

${ }^{*} W . S$ and J.S.S. contributed equally to this work.

Correspondence should be addressed to Hollis T. Cline, The Scripps Research Institute, 10550 North Torrey Pines Road, La Jolla, CA 92037. E-mail: cline@scripps.edu

DOI:10.1523/JNEUROSCI.5331-08.2009

Copyright $\odot 2009$ Society for Neuroscience $\quad$ 0270-6474/09/295032-12\$15.00/0
}

preparations containing mature neurons also increases activity indirectly and increases process outgrowth (Wayman et al., 2006). Similarly, glycinergic transmission affects dendritic arbor development, both at early stages of development, when it is depolarizing (Maric et al., 2001; Tapia et al., 2001), and later, when glycinergic transmission is inhibitory, decreasing glycinergic input increased dendritic arbor size (Sanes and Chokshi, 1992; Sanes et al., 1992; Sanes and Hafidi, 1996). Although these experiments indicate that inhibitory transmission affects dendritic arbor development, they largely relied on manipulations which can produce circuit-wide effects on activity levels that confound the interpretation of changes in neuronal structure (Ben-Ari et al., 1989; Chen et al., 1996; Tapia et al., 2001). Therefore, we sought to develop a way to interfere with inhibitory GABAergic synaptic transmission in single neurons in an otherwise intact circuit.

Postsynaptic $\mathrm{GABA}_{\mathrm{A}} \mathrm{R}$ subunit composition changes with neuronal differentiation (Maric et al., 2001; Fritschy et al., 2003; Lüscher and Keller, 2004; Mody and Pearce, 2004), such that receptors include the $\gamma 2$ subunit, which is essential for targeting receptors to postsynaptic sites (Essrich et al., 1998) and for maintaining $\mathrm{GABA}_{\mathrm{A}} \mathrm{R}$ at mature synapses (Schweizer et al., 2003). The intracellular loop (ICL) between transmembrane (TM) domains 3 and 4 of the $\gamma 2$ subunit is required to anchor receptors to postsynaptic gephyrin scaffolds (Alldred et al., 2005; Christie et al., 2006). When expressed in cultured neurons, ICL accumulates 
at inhibitory postsynaptic sites apposed to vesicular GABA transporter (VGAT) positive presynaptic terminals (Meier and Grantyn, 2004). We hypothesized that expression of ICL would interfere with anchoring $\gamma 2$ subunit-containing $\mathrm{GABA}_{\mathrm{A}} \mathrm{R}$ at inhibitory GABAergic synapses, thereby reducing GABAergic transmission in a cell-autonomous manner, whereas mutant ICL, which lacks a PKC phosphorylation site (Meier and Grantyn, 2004) would not. Using the Xenopus retinotectal system, we show that ICL expression in optic tectal neurons decreases inhibitory GABAergic synaptic transmission and interferes with both dendritic arbor development and sensory experience-dependent structural plasticity in dendrites in vivo.

\section{Materials and Methods}

Neuronal transfection and plasmid constructs. Albino Xenopus laevis tadpoles were reared from stage 23 at $16^{\circ} \mathrm{C}$ in a $12 \mathrm{~h}$ dark/ $12 \mathrm{~h}$ light cycle. To guard against any influence of circadian rhythm on arbor growth or dynamics, experiments were done at the same times in the day. At stage 47 , animals were anesthetized in $0.02 \%$ MS-222 (Sigma) and optic tectal neurons were transfected by single-cell electroporation (Haas et al., 2002; Bestman et al., 2006) with an Axoporator 800A (Axon Instruments/Molecular Devices). Using micropipettes with $\sim 1 \mu \mathrm{m}$ tip diameter filled with plasmid (3-6 $\mu \mathrm{g} / \mu \mathrm{l}$ DNA in $\mathrm{ddH}_{2} \mathrm{O}$ ), we applied stimuli of $1-2 \mu \mathrm{A}$ with $1 \mathrm{~s}$ trains of $1 \mathrm{~ms}$ square pulses at $200 \mathrm{~Hz}$ frequency. Electroporation does not cause a shift in $\left[\mathrm{Cl}^{-}\right]_{\mathrm{i}}$ in tectal neurons (Akerman and Cline, 2006). For electrophysiological recordings and expression of enhanced green fluorescent protein (EGFP)-tagged ICL (EGFP-ICL) in multiple neurons, transfection was achieved by a whole-brain electroporation protocol in which plasmid DNA was injected into the brain ventricle followed by stimulation with platinum plate electrodes using a SD9 stimulator (Grass Technologies). The settings used were as follows: five exponential decay pulses with $1.6 \mathrm{~ms}$ duration with $50 \mathrm{~V}$ at $1 \mathrm{~Hz}$ (Haas et al., 2002).

To determine the distribution of exogenously expressed ICL, we expressed the murine sequence of ICL (kindly provided by Dr. Simon Rumpel, The Research Institute of Molecular Pathology, Vienna, Austria), which was cloned into a pEGFP-N1 backbone (Clontech) to produce an EGFP-ICL fusion protein. For all other experiments, ICL was cloned into a bidirectional PCS2 plasmid (kindly provided by Dave Turner, University of Michigan Medical School, Ann Arbor, MI) with two independent cytomegalovirus promoters, one driving the ICL sequence and another one driving cytosolic EGFP. The TdTomato sequence (kindly provided by Roger Tsien, Howard Hughes Medical Institute, University of California, San Diego, San Diego, CA) was cloned into the pEGFP-N1 backbone after removal of the EGFP sequence. Mutant ICL (mICL) was generated by exchanging Ser (S) to Ala (KNPLLRMFSFKAPTIDIRPRSATIQ) of ICL sequence. In all cases, plasmids were sequenced and digested to confirm correct cloning.

The degree of conservation of rodent and frog sequences for ICL was judged by alignments with BlastX using the mouse sequence of ICL (from NM_008073.2) to query the JGI Xenopus tropicalis assembly (v.4.1), which in turn returned the annotated gene e_gw1.813.18.1 (whose gene ontology, GO id 0004890 , corresponds to $\mathrm{GABA}_{\mathrm{A}} \mathrm{R} \gamma 2$ subunit) and an EST (CAAJ 16524) that likely corresponds to the shortened version of ICL lacking the LLRMFSFK sequence (Baer et al., 2000; Meier and Grantyn, 2004).

Western blots. Stage 47 tadpole midbrains were dissected and homogenized in radioimmunoprecipitation assay (RIPA) buffer. Protein homogenates were separated by SDS-PAGE (PAGE) and transferred to nitrocellulose membranes. Blots were blocked in 5\% nonfat milk with $0.1 \%$ TBS and Triton X-100 (Sigma) and incubated with primary antibodies diluted in blocking solution. Rabbit polyclonal GABA $\mathrm{R} \gamma 2$ antibody (ab4073, Abcam) was used. Blots were rinsed and either incubated with biotinylated anti-rabbit Ig (Amersham Biosciences) with HRPconjugated streptavidin (Amersham Biosciences) or directly with HRPlinked mouse IgG. Bands were visualized using ECL chemiluminescence (Amersham Biosciences).

Immunofluorescent staining and quantification. Anesthetized stage 47 tadpoles were dissected to remove the skin and meninges over the brain. Animals were transferred to $4 \%$ paraformaldehyde (Electron Microscopy Sciences) in phosphate buffer ( $\mathrm{PB}, \mathrm{pH}$ 7.4), exposed to a brief microwave pulse (1 min on, 1 min off, 1 min on, Pelco Biowave Pro 36500 ), and left to fix for an additional $1 \mathrm{~h}$ at room temperature. Animals were cryoprotected overnight in 30\% sucrose (Sigma) and brains were cut into $20 \mu \mathrm{m}$ cryostat sections. Sections were quenched (50 mM ammonium chloride, Sigma), permeabilized (1\% Triton X-100), blocked [5\% goat serum (Invitrogen) in 1\% Triton X-100], and incubated in primary antibodies (in 2\% serum in $0.1 \%$ Triton X-100) overnight at $4^{\circ} \mathrm{C}$. Antibodies used were: rabbit polyclonal $\mathrm{GABA}_{\mathrm{A}} \mathrm{R} \gamma 2$, rabbit polyclonal VGAT (Synaptic Systems), goat polyclonal GABA $\mathrm{A} \alpha 2$ (s.c. 7350, Santa Cruz Biotechnology), and mouse monoclonal anti-GFP (Rockland). Sections were rinsed and incubated in secondary antibodies (in $0.1 \%$ Triton X-100): Alexa Fluor 568/633 goat anti rabbit, Alexa Fluor 488 goat anti-mouse/rabbit (Invitrogen). Sections were mounted in Vectashield with or without Propidium Iodide stain (Vector Laboratories) and imaged using an Olympus Fluoview FV300 with a LUMPlanFl/IR $60 \times$ water-immersion objective [Olympus; numerical aperture (NA), 1.1] (Ruthazer et al., 2006). Confocal images were obtained sequentially with the two different laser excitations (to minimize bleed-through). Brain sections selected for confocal imaging correspond to an approximate $100 \mu \mathrm{m}$ depth from brain surface.

To quantify the distribution of immunoreactivity, fluorescent intensity profiles were measured along dendrites and across somata with ImageJ (W. Rasband, NIH, Bethesda, MD). For analysis of VGAT and EGFP distribution, images were collected at nonsaturating conditions in single optical slices $(1.5 \mu \mathrm{m})$. We selected the regions of interest where the dendritic tracts were EGFP-ICL positive. Receptor clusters were identified by intensity values two-folder larger than local diffusion fluorescence and with target size between $0.2-2 \mu \mathrm{m}$ in diameter by Imaris (Alldred et al., 2005). Custom software written in Matlab (MathWorks) was used for colocalization and shift analyses. ICL puncta were considered colocalized with VGAT when the centers of the ICL and VGAT puncta were within 2 $\mu \mathrm{m}$ of each other. We used shift analysis to determine whether the colocalization was caused by random alignment of VGAT and ICL puncta. Briefly, the ICL channel was displaced relative to the VGAT channel by a random vector whose length was between 1 and $10 \mu \mathrm{m}$. After displacement, the $x$ and $y$ coordinates of the ICL puncta were computed with modular arithmetic, so that no displaced puncta fell outside of the field of view containing the VGAT puncta. After 1000 random displacements, a $p$ value was computed as the fraction of shifted colocalization that was greater than or equal to the unshifted colocalization.

Two-photon imaging and morphometric analysis. Starting $1 \mathrm{~d}$ after electroporation, stage 47 tadpoles were anesthetized in $0.02 \%$ MS-222 and mounted under glass coverslips in a custom-built chamber. Fluorescent tectal neurons were imaged in vivo with a custom-built laser scanning two-photon microscope modified from a Olympus Fluoview FV300 confocal scanbox mounted on a Olympus BXSOW1 microscope (Ruthazer et al., 2006). The light source was a Tsunami femptosecond-pulsed Ti: sapphire laser pumped by a 10W solid-state Millenia X laser (both from Newport Spectra Physics) Image stacks $(0.5-1 \mu \mathrm{m} z$ interval) were collected using a LUMPlanFl/IR $60 \times$ water-immersion objectives (either 0.9 or $1.1 \mathrm{NA}$, Olympus).

Three-dimensional reconstruction of dendritic arbors using optical stacks was performed to determine morphometric parameters [total dendritic branch length (TDBL), branch number, branch lengths] using Imaris 5.5 with Filament Tracer (Bitplane). Average segment lengths (ASL) were determined by measuring distances between branch tips and branch points, the starting point is the first branch point of the primary dendrite. Two-dimensional projections of optical stacks in orientations were used to determine the maximal dendritic arbor angle. These images were then exported to ImageJ for further measurements of dendritic tree angle, maximal length and dendritic arbor projected area. Angles were measured on projected images using the exit point of the main dendrite from the soma as the vertex. The two rays were drawn tangentially to the dendritic tree to include the whole tree area excluding the axon. Maximal length was estimated as the distance between the vertex and the farthest dendritic branch tip. Areas were estimated using 
the angle and the maximal lengths to draw a polygon that includes the full dendritic tree. Analysis of branch dynamics was performed as described previously (Sin et al., 2002).

Visual stimulation. To test the effects of visual stimulation, animals were anesthetized and neurons were imaged $24 \mathrm{~h}$ after electroporation. After recovering from anesthesia, freely swimming animals were placed in a dark chamber for $4 \mathrm{~h}$. At the end of this period, the same neurons were imaged again, after which animals were placed into a chamber with a $3 \times 4$ panel of green light-emitting diodes (LEDs; AND191GCP, Allied Electronics) turning on and off sequentially ( $1 \mathrm{~s}$ at $0.2 \mathrm{~Hz}$ with $1 \mathrm{~s}$ of no light between cycles). After $4 \mathrm{~h}$ of visual stimulation, animals were imaged for the third time (Sin et al., 2002).

Electrophysiology. For whole-cell recordings, tadpoles at stage $47 / 48$ were anesthetized with $0.02 \%$ MS-222, and brains were dissected and filleted along the dorsal midline (Akerman and Cline, 2006). The brains were perfused with extracellular saline containing (in $\mathrm{mm}$ ): $115 \mathrm{NaCl}, 2$ $\mathrm{KCl}, 3 \mathrm{CaCl}_{2}, 1.5 \mathrm{MgCl}_{2}, 5 \mathrm{HEPES}, 10$ glucose, and 0.01 glycine, $\mathrm{pH} 7.2$, osmolality $255 \mathrm{mOsm}$ throughout the recording. Experiments were performed at room temperature $\left(20-22^{\circ} \mathrm{C}\right)$. For electrical stimulation experiments, a bipolar stimulating electrode (Frederick Haer Company) was placed in the optic chiasm to activate retinal ganglion cell (RGC) axons. Synaptically evoked currents were recorded from optic tectal neurons using a $\mathrm{K}^{+}$-based intracellular solution (in mM: $110 \mathrm{~K}$-gluconate, 8 $\mathrm{KCl}, 5 \mathrm{NaCl}, 1.5 \mathrm{MgCl}_{2}, 20$ HEPES, 0.5 EGTA, 2 ATP, and $0.3 \mathrm{GTP}$ ), whereas spontaneous miniature IPSCs or EPSCs (mIPSCs and mEPSCs) were recorded using a $\mathrm{Cs}^{+}$-based intracellular solution (in mM: $114 \mathrm{Cs}-$ methane sulfonate, $1.5 \mathrm{MgCl}_{2}$, 3 TEA-Cl, 20 HEPES, 10 EGTA, 2 ATP, and $0.3 \mathrm{GTP}$ ). The membrane potential was voltage clamped at $-60 \mathrm{mV}$ to record AMPA receptor (AMPAR)-mediated currents or at $0 \mathrm{mV}$ to record $\mathrm{GABA}_{\mathrm{A}} \mathrm{R}$-mediated currents. TTX ( $1 \mu \mathrm{M}$; Alomone Labs) and DL-APV (100 $\mu \mathrm{M}$; Tocris Cookson) were included in the extracellular saline when recording mIPSCs or mEPSCs. As required, the superfusion saline was supplemented with DL-APV or diazepam ( $2 \mu \mathrm{M}$; Sigma) when testing benzodiazepine sensitivity. For consistency, all cells were recorded from the middle of the tectum. Recording micropipettes were pulled from borosilicate glass capillaries and had resistances in the range of 7-9 M $\Omega$. Liquid junction potential was adjusted during recording. Recordings were accepted for analysis from cells in which the series resistance did not change $>10 \%$ and input resistance $(0.7-2 \mathrm{G} \Omega)$ remained relatively constant. Signals were sampled at $10 \mathrm{kHz}$ and filtered at $2 \mathrm{kHz}$ with a Multiclamp 700B amplifier (Molecular Devices). Data were analyzed using ClampFit 10 (Molecular Devices). Five minute periods of mIPSC or mEPSC recordings were analyzed with the Synaptosoft Mini Analysis Program.

Statistical tests. Mann-Whitney tests were used to test for significance of morphometric data. Wilcoxon signed rank tests were used for paired data. Where noted, Student's $t$ test or Kolmogorov-Smirnov test (K-S test) was used. Data are presented as individual data points or as mean \pm SEM, unless otherwise noted. Experiments and analysis were performed blind to the experimental condition.

\section{Results}

Experiments were performed on Xenopus tadpoles between stages 47 and 48 when GABAergic transmission is hyperpolarizing (Akerman and Cline, 2006) (Fig. 1A).

\section{$\mathrm{GABA}_{\mathrm{A}} \mathrm{R} \gamma 2$ subunit in the Xenopus visual system}

The $\gamma 2$ subunit including the sequence corresponding to ICL is highly conserved between frog and mouse (Fig. $1 B$ ). To test whether the $\gamma 2$ subunit protein is present in Xenopus optic tectum, we isolated the midbrain area and immunoblotted the protein extracts using an antibody against the rodent ICL sequence (Fig. 1C, diagram). A band with a similar apparent molecular weight as from rat brain extracts is detected (Fig. $1 C$, right panel) indicating the $\gamma 2$ subunit is expressed in the midbrain of tadpole. Fluorescent immunocytochemistry shows that the $\gamma 2$ subunit is expressed in tectal neurons with a punctate pattern in the soma and neuropil (Fig. 1D), consistent with observations in other vertebrate brain areas (Gutiérrez et al., 1994; Essrich et al., 1998; Kittler et al., 2000; van Rijnsoever et al., 2005). These data indicate that the $\mathrm{GABA}_{\mathrm{A}} \mathrm{R} \gamma 2$ subunit is present in the optic tectum of $X$. laevis.

\section{Distribution of exogenously expressed ICL}

To assess the distribution of exogenously expressed ICL, tectal neurons were electroporated with the cytosolic marker TdTomato to reveal cell morphologies, and the ICL sequence fused with the reporter EGFP at its N-terminal (EGFP-ICL). TdTomato expression shows the typical organization of tectal neurons, with closely packed cell bodies and dendrites extending toward the tectal neuropil. Expression of EGFP-ICL results in labeling along the perimeter of the soma and dendrites (Fig. $2 A$, left; $B$, top left). Single optical sections through spatially isolated EGFPICL-expressing cells (Fig. $2 \mathrm{~B}$ ) show a punctate distribution of EGFP-ICL along dendrites compared with TdTomato which is evenly distributed in the soma and dendrites (Fig. $2 \mathrm{~B}$, bottom left). The punctate distribution of EGFP-ICL was further demonstrated by fluorescent intensity measurements along dendrites (Fig. $2 B$, right diagram and graph).

To test whether EGFP-ICL accumulates at inhibitory synapses, we determined the codistribution of a well established inhibitory presynaptic terminal marker, VGAT (Schweizer et al., 2003; Meier and Grantyn, 2004; Gillespie et al., 2005) with EGFPICL puncta. In cryosections, VGAT immunoreactivity is strong in the tectal neuropil where it labels puncta (Fig. 2C, middle panel) as reported in other systems (Essrich et al., 1998; Crestani et al., 1999; Schweizer et al., 2003; Meier and Grantyn, 2004; Gillespie et al., 2005). Analysis of the codistribution of VGAT with EGFP-ICL, detected with GFP antibody, indicates that $67.8 \pm 6.0 \%$ of the EGFP-ICL puncta are apposed to VGATpositive puncta, similar to findings in cultures of embryonic spinal cord neurons (Meier and Grantyn, 2004). Shift analysis confirmed that the colocalization is not caused by random alignment between EGFP-ICL and VGAT puncta $(p<0.001$, see Materials and Methods for details). These data indicate that EGFP-ICL accumulates in puncta apposed to inhibitory presynaptic sites.

\section{ICL expression disrupts GABAergic synaptic transmission}

We examined whether inhibitory GABAergic synaptic transmission is affected by ICL expression. Our hypothesis from the double-staining experiments predicts that ICL will occupy binding sites at inhibitory synaptic scaffolds and prevent anchoring of $\gamma 2$ subunit-containing $\mathrm{GABA}_{\mathrm{A}} \mathrm{R}$ at synapses. To test this possibility, tectal neurons were transfected with a dual promoter plasmid expressing EGFP and ICL or EGFP and the mutant ICL, mICL, or control plasmids expressing EGFP only. We recorded $\mathrm{GABA}_{\mathrm{A}} \mathrm{R}$-mediated mIPSCs from control EGFP-, mICL-, and ICL-expressing neurons. We find that $36 \%$ (17 of 47) of ICLexpressing neurons have no spontaneous GABAergic mIPSCs, compared with $3 \%$ ( 1 of 28 ) of EGFP-expressing neurons or $5 \%$ ( 1 of 18) of mICL-expressing neurons, indicating that ICL expression completely blocks GABAergic transmission in about one-third of neurons (Fig. $3 A, B$ ).

We characterized the GABAergic and glutamatergic transmission onto the ICL-expressing neurons which still had GABAergic inputs (Fig. 3C). The average interevent interval (IEI) of mIPSCs on these neurons was significantly greater in ICL-expressing neurons compared with EGFP- or mICL-expressing controls (Fig. $3 D, E)$, whereas the amplitudes of $\mathrm{GABA}_{\mathrm{A}} \mathrm{R}$-mediated mIPSCs 

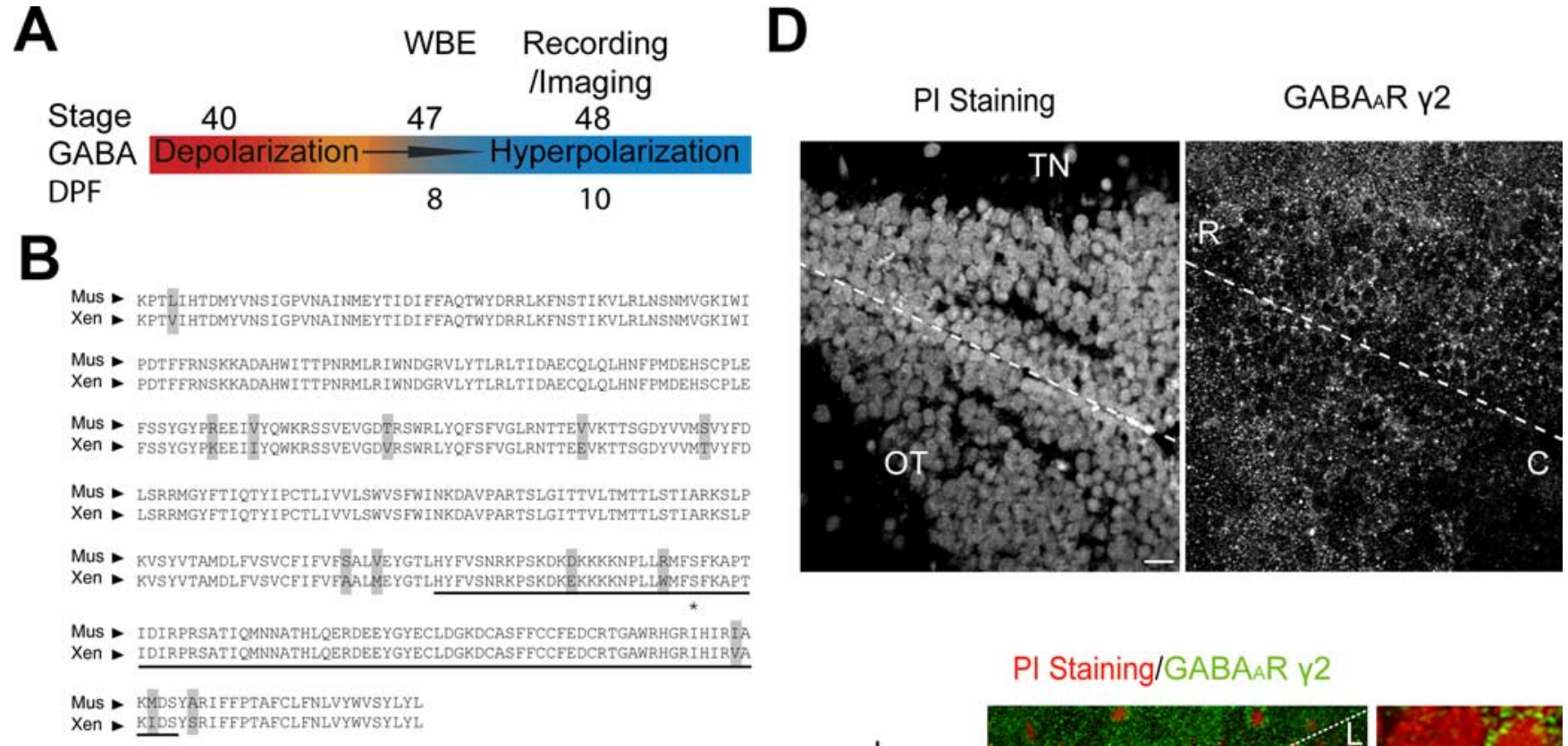
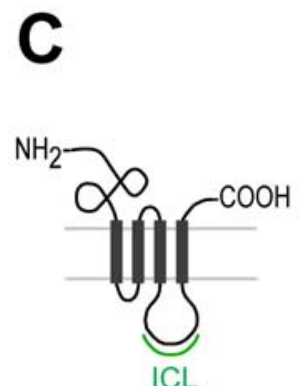

GABAAR y2 subunit expression

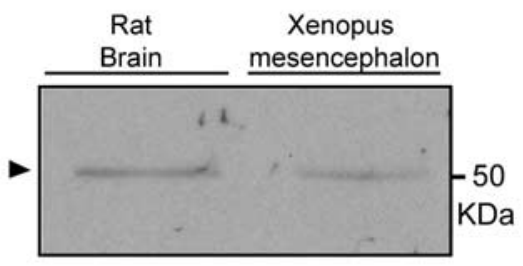

PI Staining/GABAAR Y2

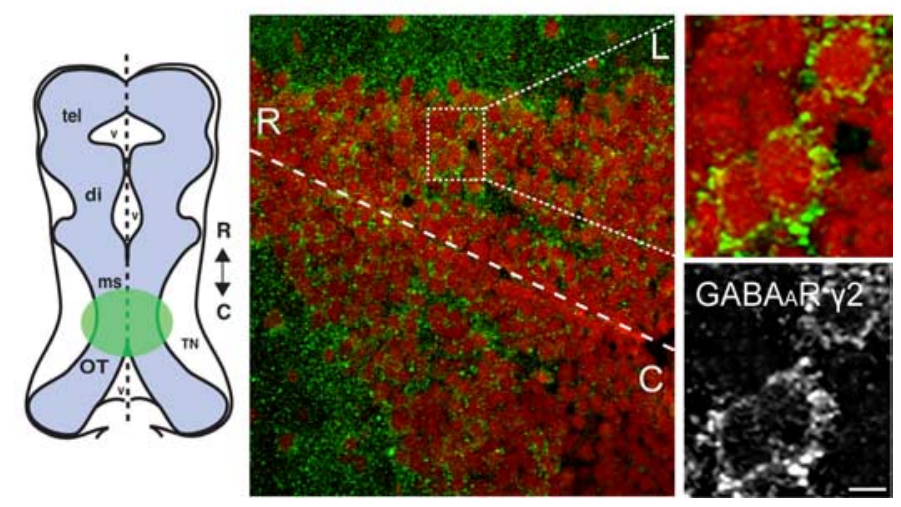

Figure 1. Xenopus $\mathrm{GABA}_{\mathrm{A}} \mathrm{R} \gamma 2$ subunit. $\boldsymbol{A}$, We transfected tadpoles by whole-brain electroporation (WBE) at stage 47 corresponding to $\sim 8 \mathrm{~d}$ post-fertilization (DPF) when GABAergic transmission is hyperpolarizing. We performed imaging or electrophysiology experiments $1-3 \mathrm{~d}$ after electroporation when animals are between stage 47 and 48 . $B$, Amino acid sequence alignment between a portion of the mouse $G A B A_{A} R \gamma 2$ subunit (Mus) and the corresponding portion of the predicted Xenopus (Xen) $\gamma 2$ subunit. The sequence is identical except for conservative amino acid substitutions, which are shaded with gray. The black line underlines the sequence corresponding to the $\gamma 2$ ICL. Asterisks mark the site in mutant ICL where Ser (S) is exchanged for Ala (A). C, Western blot using an antibody raised against the rat ICL (left diagram) identifies bands in rat brain and Xenopus midbrain extracts with the expected molecular weight of $\mathrm{AABA}_{A} \mathrm{R} \gamma 2$ subunit $(n=3$ experiments). $\boldsymbol{D}$, Immunolabeled cryosections of Xenopus optic tectum [green-shaded area in diagram of section display a punctate-labeling pattern in the optic tectal neuropil and in the periphery of optic neuron soma, which was identified with the nuclear stain marker propidium iodide (PI)]. Dotted line marks midline. Scale bar, $20 \mu \mathrm{m}$. Inset (dotted line box in merge panel) highlights ring-like pattern of labeling in the cell body layer of the optic tectum. Scale bar, $5 \mu \mathrm{m}$. tel, Telencephalon; di, diencephalon; ms, mesencephalon; $0 \mathrm{~T}$, optic tectum; TN, tectal neuropil; $\mathrm{V}$, ventricles; $R$, rostral; C, caudal; L, lateral.

were not statistically different (Fig. $3 F)$. In contrast, the amplitude and IEI of spontaneous AMPAR-mediated mEPSCs in ICLexpressing neurons were not significantly different from EGFPor mICL-expressing cells (Fig. 3G-J). To test whether the decrease in mIPSC frequency might be caused by a change in presynaptic release probability, we recorded pairs of evoked GABAergic synaptic currents with different interstimulus intervals (ISI), ranging from 20 to $200 \mathrm{~ms}$ (Fig. 4A). We did not detect a significant difference in paired pulse ratios of $G_{A B A} R$ mediated synaptic currents over the ISIs tested (Fig. $4 B$ ). Furthermore, EGFP- and ICL-expressing neurons generated similar spike numbers in response to injected current pulses, indicating that ICL expression does not affect neuronal excitability (Fig. $4 C, D)$. These data indicate that ICL expression completely blocks GABAergic inputs onto about one-third of neurons and decreases GABAergic input in the remainder of ICL-expressing neurons by decreasing the number of GABAergic synapses without changing release probability and neuronal excitability.

To test whether ICL expression affects the balance of excita- tion to inhibition, we collected whole cell recordings of optic nerve stimulation-evoked synaptic responses sequentially at 0 $\mathrm{mV}$ and $-60 \mathrm{mV}$. This allowed us to record $\mathrm{GABA}_{\mathrm{A}} \mathrm{R}$-mediated and AMPAR-mediated synaptic inputs from the same neurons (Fig. $4 E$ ). When we normalize the evoked $\mathrm{GABA}_{\mathrm{A}} \mathrm{R}$ synaptic responses to the AMPAR responses, we find that ICL-expressing neurons have a significantly decreased ratio of $\mathrm{GABA}_{\mathrm{A}} \mathrm{R}$ - to AMPAR-mediated currents compared with EGFP- or mICLexpressing neurons (Fig. $4 F$ ). This analysis demonstrates that ICL expression selectively decreases inhibitory input relative to glutamatergic excitatory input onto optic tectal neurons.

Most $\mathrm{GABA}_{\mathrm{A}} \mathrm{R}$ contain a binding site for benzodiazepines that is located at the interface of the $\gamma 2$ and $\alpha$ subunits (Wallace et al., 2001; Sigel, 2002). To test whether ICL depletes synapses of $\gamma 2$ subunit-containing receptors, we recorded evoked $G_{A B A} R$ mediated synaptic currents before and after $10 \mathrm{~min}$ perfusion of diazepam, a classical benzodiazepine agonist (Fig. 4G) (Sigel, 2002). In control neurons, diazepam increases the $G_{A B A} R$ mediated currents, but ICL-expressing neurons do not increase 
A

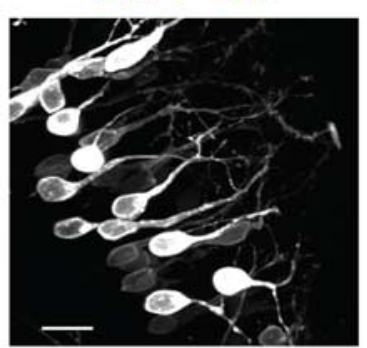

TdTomato

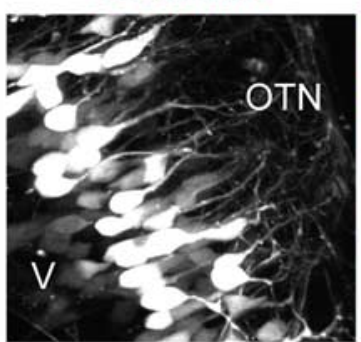

TdTomato/EGFP-ICL

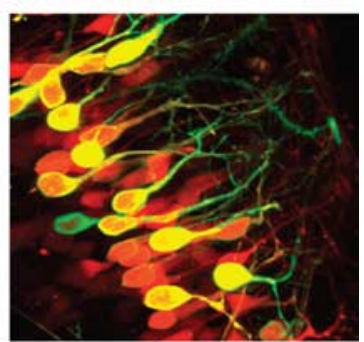

B
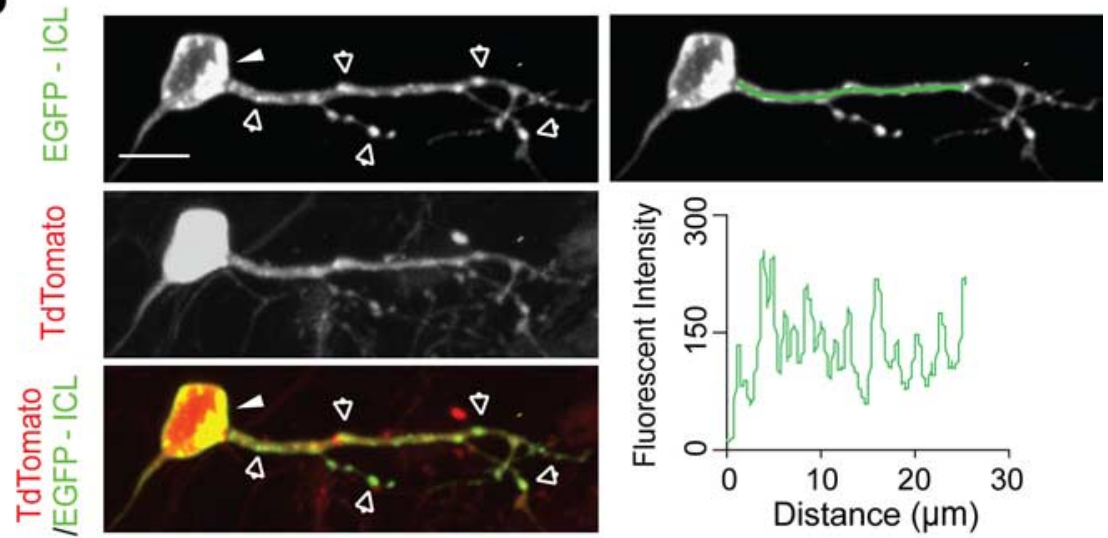

C
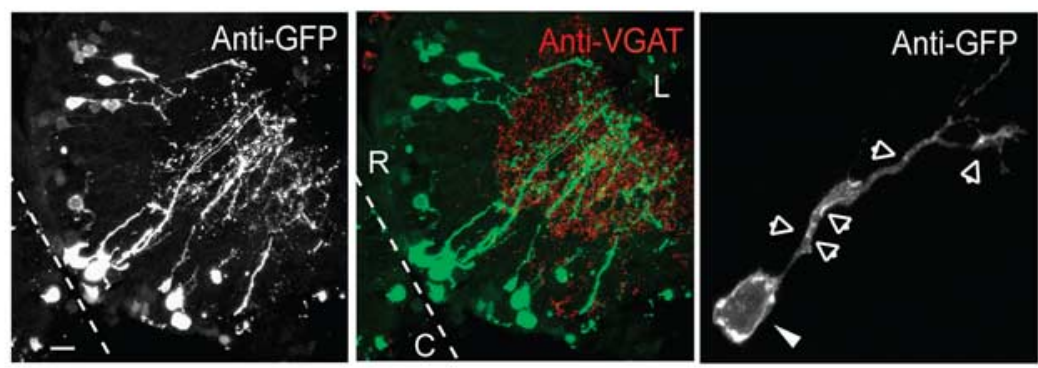

D
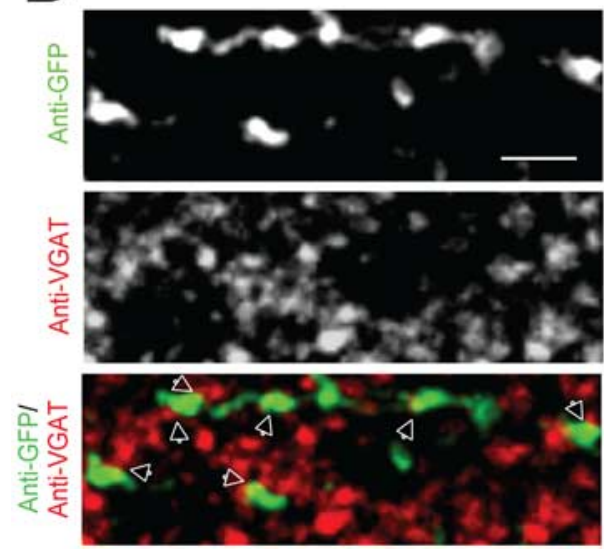

E

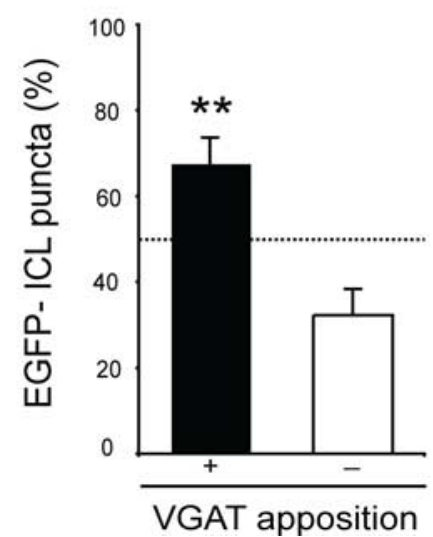

Figure 2. Distribution of EGFP-ICL in optic tectal neurons. $\boldsymbol{A}$, Coexpression of EGFP-ICL and TdTomato in optic tectum, shown as separate EGFP and TdTomato images and the merged image. Images are maximal projection Zstacks through $100 \mu \mathrm{m}$ depth. OTN (optic tectal neuropil), V (ventricle). Scale bar, $10 \mu \mathrm{m}$. B , Distribution of EGFP-ICL (top left), TdTomato (middle left), and merged image (bottom left) shown in images of single optical sections. TdTomato distributes evenly along dendrites and across the soma (middle left). EGFP-ICL fluorescence is more intense at the periphery of the soma (white arrowheads in images, top left) and is distributed in discrete fluorescent peaks along dendrites (intensity plot on right, generated from dendrite shown in top left panel). Scale bar, $10 \mu \mathrm{m}$. C, Cryosection of optic tectum transfected with EGFP-ICL and double-immunolabeled with antibodies specific to GFP (anti-GFP, green) and VGAT (anti-VGAT, red) shows VGAT immunostained puncta in the neuropil (red, middle). GFP immunoreactivity identifies EGFP-ICL electroporated neurons (left, middle panels). Single optical sections (right panel) show EGFP-ICL

evoked $\mathrm{GABA}_{\mathrm{A}} \mathrm{R}$-mediated responses with diazepam (Fig. $4 H$ ). Together, the electrophysiology experiments indicate that the ICL expression blocks or decreases $\mathrm{GABA}_{\mathrm{A}} \mathrm{R}$-mediated synaptic responses. The electrophysiology data and immunofluorescent staining data are consistent with the idea that ICL interferes with controlling $\gamma 2$ subunit-containing $\mathrm{GABA}_{\mathrm{A}} \mathrm{R}$ residence at postsynaptic sites.

\section{ICL expression alters dendritic}

arbor development

To test whether reduced GABAergic synaptic transmission affects the development of dendritic structure, we collected timelapse images of single tectal neurons expressing EGFP and ICL or EGFP alone in live stage 47 Xenopus tadpoles (Bestman et al., 2006) when GABAergic transmission is inhibitory (Akerman and Cline, 2006). Neurons were imaged at daily intervals over $3 \mathrm{~d}$ starting $1 \mathrm{~d}$ after single cell electroporation. Although the structure of the dendritic arbors of control and ICLexpressing neurons are comparable on the first observation (Fig. 5A) (EGFP, ICL: $24 \mathrm{~h}$ ), ICL-expressing neurons progressively acquire a broader dendritic arbor over the next $2 \mathrm{~d}$ and fail to develop the increased branch density characteristic of control neurons (Fig. 5A).

To quantify these features of arbor structure, we used two morphometric measurements to assess arbor span (Martin and Whitteridge, 1984; Borba et al., 2000; Coleman and Friedlander, 2002; Shapiro et al., 2005; Smear et al., 2007). We analyzed the maximal angle and the maximum projected area of the dendritic arbor (Fig. 5A, far right panels). Whereas both control and ICL-expressing neurons increased dendritic arbor areas over $72 \mathrm{~h}$ of imaging (Fig. $5 B, C$ ), only ICL-expressing neurons increased arbor angles over the $3 \mathrm{~d}$ imaging period (Fig. $5 B, C$ ). Plotting arbor angle versus arbor area shows a clear segregation of the population of control and ICL-expressing neurons (Fig. 5D). In contrast, the maximum linear distance between the cell body and the farthest den-

\section{$\leftarrow$}

puncta in dendrites (open arrows) and at the periphery of the cell body (white arrowhead). Dotted lines in left and middle panels mark midline. R, Rostral; C, caudal; L, lateral. Scale bar, $10 \mu \mathrm{m}$. D, Codistribution of EGFP-ICL and VGAT in single optical sections through tectal neuropil. Images of labeling for anti-GFP (top), anti-VGAT (middle), and merged images (bottom). Open arrows mark examples of EGFP apposing VGAT puncta. Scale bar, $5 \mu \mathrm{m}$. E, A majority of EGFP-ICL puncta are apposed to VGAT puncta ( $n=3$ independent experiments, ${ }^{* *} p<0.01$, Student's $t$ test). 

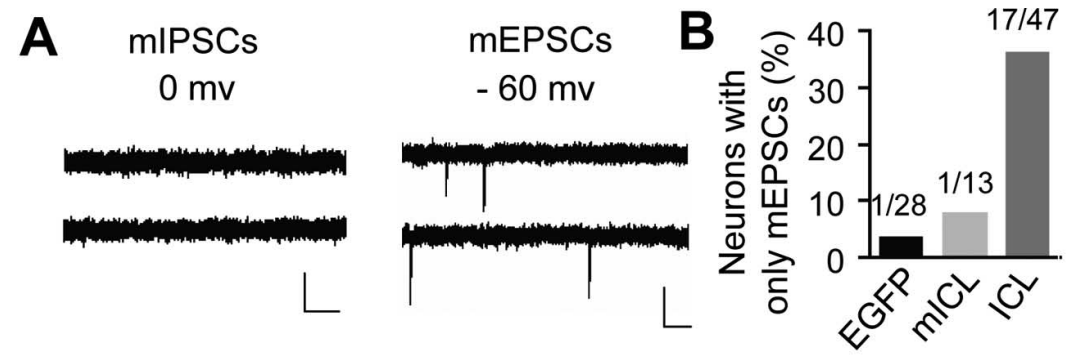

C EGFP

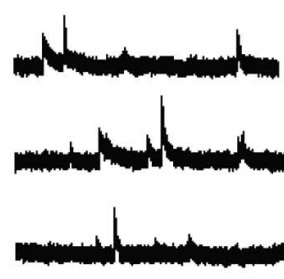

D

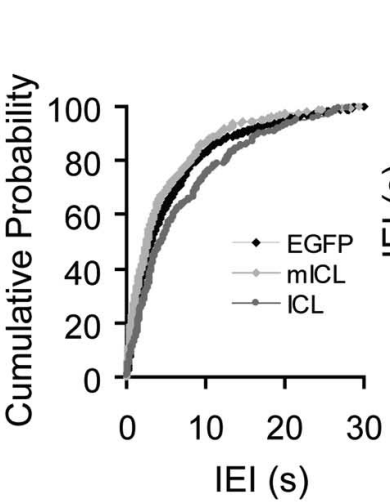

G

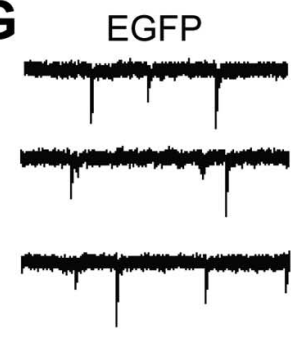

H

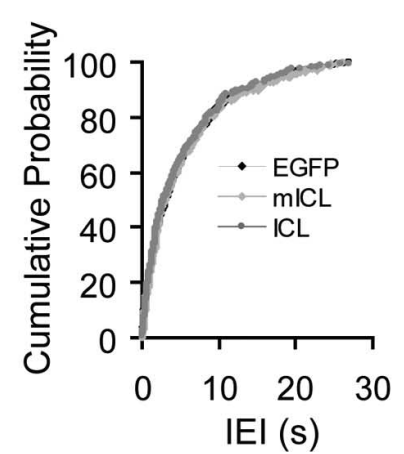

$\mathrm{mICL}$

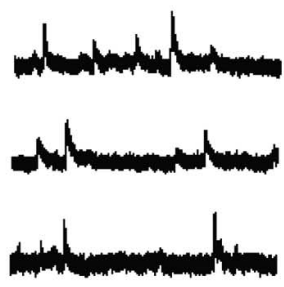

E

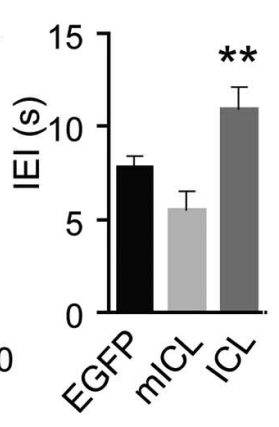

$\mathrm{mlCL}$

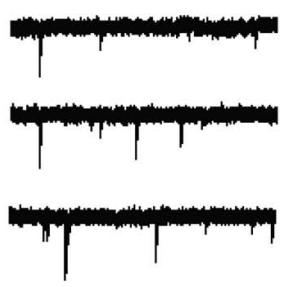

I

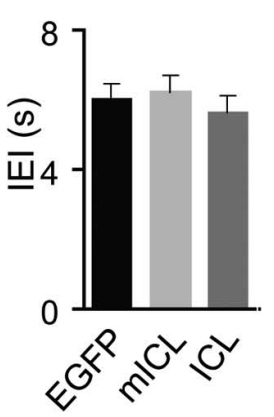

ICL
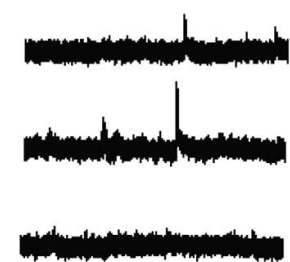

$F$
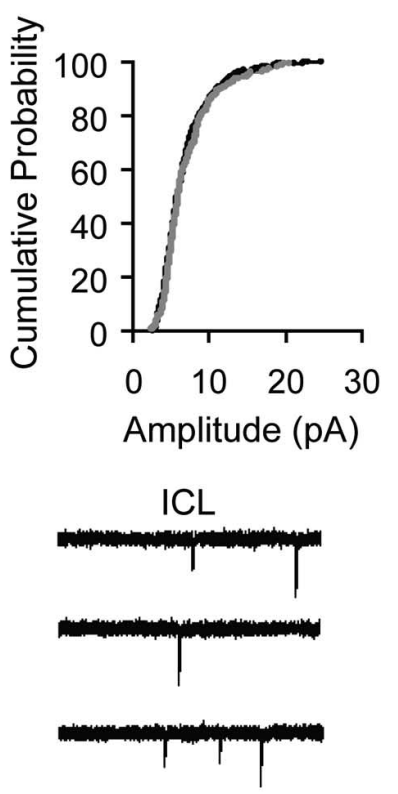

J

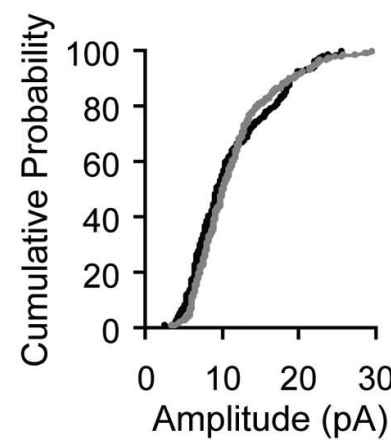

Figure 3. ICL expression disrupts $\mathrm{GABA}_{\mathrm{A}} \mathrm{R}$-dependent synaptic transmission. $A$, Traces from an ICL-expressing neuron without mIPSCs (calibration: $10 \mathrm{pA}, 200 \mathrm{~ms}$ ) but with mEPSCs (calibration: $20 \mathrm{pA}, 100 \mathrm{~ms}$ ), recorded at $0 \mathrm{mV}$ and $-60 \mathrm{mV}$, respectively, $3 \mathrm{~d}$ after transfection. $\boldsymbol{B}$, ICL expression blocks GABAergic synaptic transmission in $36 \%$ of neurons. Only $3 \%$ of EGFP-expressing control neurons or $5 \%$ of mICL-expressing neurons have no detectable mIPSCS. C, GABAergic synaptic transmission is altered in the remaining $64 \%$ of ICL-expressing neurons. Representative recordings of mIPSCs from EGFP- (left), mICL- (middle), and ICL- (right, calibration: $10 \mathrm{pA}, 200 \mathrm{~ms}$ ) expressing tectal neurons. $\boldsymbol{D}, \boldsymbol{E}$, Normalized cumulative probability curves $(\boldsymbol{D})$ and mean values $(\boldsymbol{E})$ (EGFP: $n=28, \mathrm{mICL}: n=18, \mathrm{ICL}: n=30$ cells) show that the IEl of GABA ${ }_{A} \mathrm{R}$-mediated currents in ICL-expressing neurons was

dritic branch tip was not significantly different between ICL-expressing neurons and controls (EGFP: $24 \mathrm{~h}, 81.31 \pm 5.58$ 72 h, $92.31 \pm 4.02$; ICL: 24 h, $94.80 \pm 6.16$; $72 \mathrm{~h}, 100.00 \pm 5.48)$. Furthermore, plotting arbor angle versus maximal length shows no segregation of ICL-expressing neurons from control neurons (Fig. $5 E$ ). These findings indicate that reduced inhibitory GABAergic synaptic input may lead to significant changes in dendritic arbor shape over time and alters the distribution of dendritic branches within the neuropil.

To analyze further the changes of dendritic arbor structure that occur with ICL expression, we compared dendritic branch tip numbers, TDBL, and branch segment lengths at each time point from 3 dimensional reconstructions of EGFP- and ICLexpressing neurons. Although control and ICL-expressing neurons have similar branch tip numbers on the first day of imaging, control neurons increase branch tip numbers at each daily interval over $3 \mathrm{~d}$ whereas ICL-expressing neurons have significantly fewer branch tips than controls at the 48 and $72 \mathrm{~h}$ time points (Fig. $5 F$ ). In contrast, TDBL in ICL-expressing neurons is comparable to control neurons at each time point (Fig. 5G). The decrease in branch tip number without a corresponding decrease in TDBL indicates that ICL expression reduces dendritic arbor branch density, as seen in the representative neurons in Figure 5A. As an independent measure of arbor branch density, we determined the average length of individual dendritic segments (or average segment length) over $3 \mathrm{~d}$. Average branch segment lengths in control and ICL-expressing neurons were comparable on the first day of imaging, but were significantly less in ICL-expressing neurons than controls at the 48 and $72 \mathrm{~h}$ time points (Fig. $5 \mathrm{H}$ ), indicating that arbor density is decreased in ICL-expressing neurons. Together, these results indicate that reduced inhibitory GABAergic transmission affects dendritic

significantly increased compared with EGFP- or mICLexpressing neurons $\left({ }^{* *} p<0.001, K-S\right.$ test $) . \boldsymbol{F}$, Amplitudes of mIPSCs were not significantly different ( $p>0.05, \mathrm{~K}-\mathrm{S}$ test). Neurons displaying IEls $>30$ s were not included in the analysis. $\mathbf{G}$, Representative recordings of mEPSCs from EGFP(left), mICL- (middle) and ICL-expressing (right; calibration: $20 \mathrm{pA}, 100 \mathrm{~ms}$ ) tectal neurons. Normalized cumulative probability curves $(\boldsymbol{H}, \boldsymbol{J})$ and means $(\boldsymbol{I})$ of AMPAR-mediated currents (EGFP: $n=27, \mathrm{mICL}: n=18, \mathrm{ICL}: n=21$ ) show that neither IEI nor amplitudes of mEPSCs in ICL-expressing neurons were significantly different from EGFP-expressing cells (IEl: $p>0.05$; amplitudes: $p>0.05, \mathrm{~K}-\mathrm{S}$ test). 
A

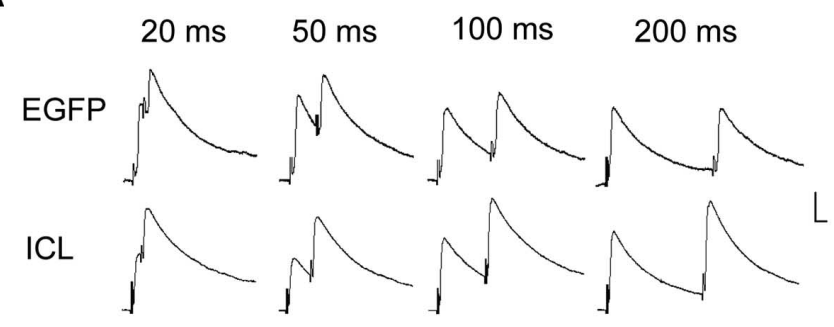

C

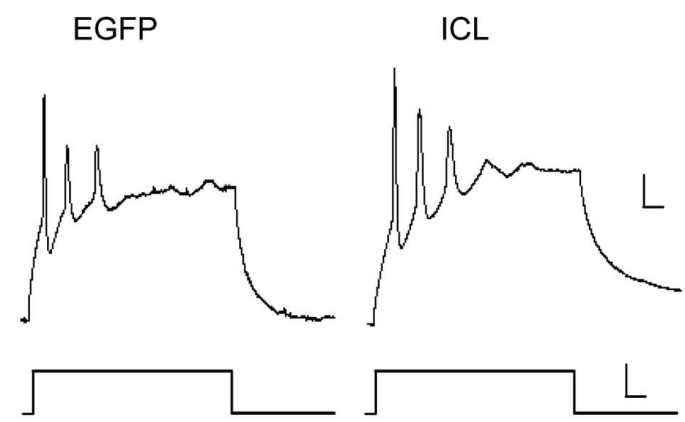

B

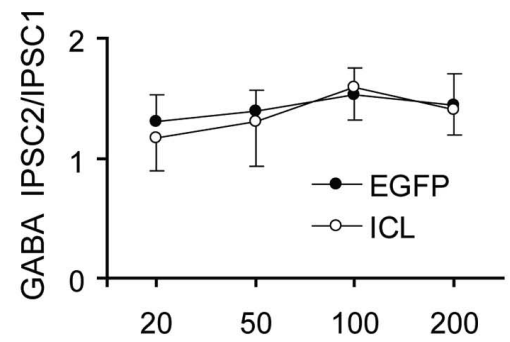

D

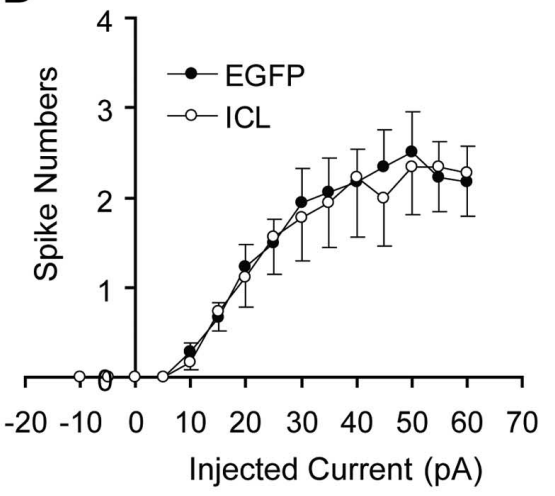

E

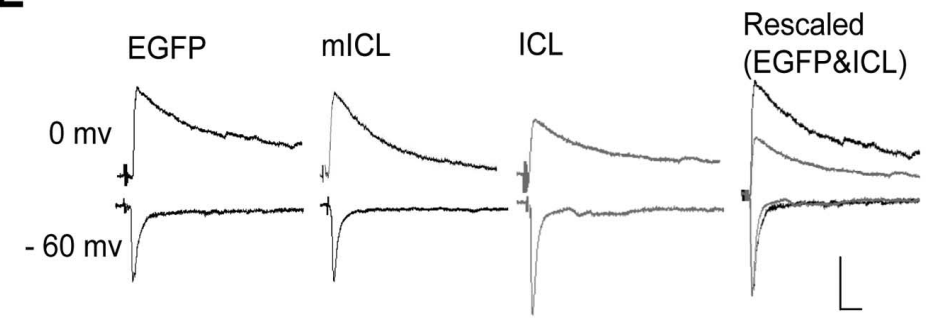

G

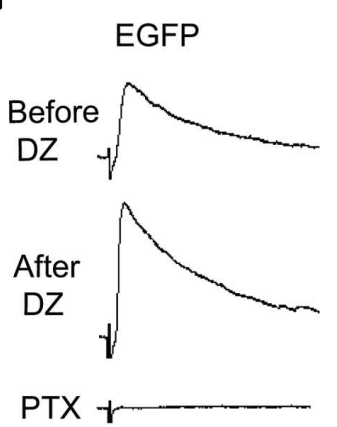

$\mathrm{mICL}$
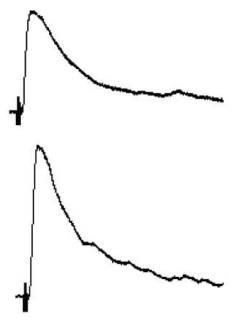

$+$

ICL

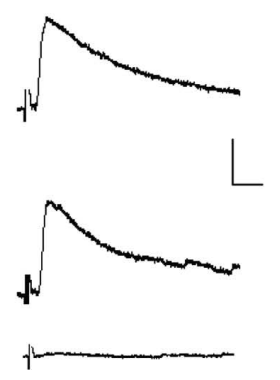

F

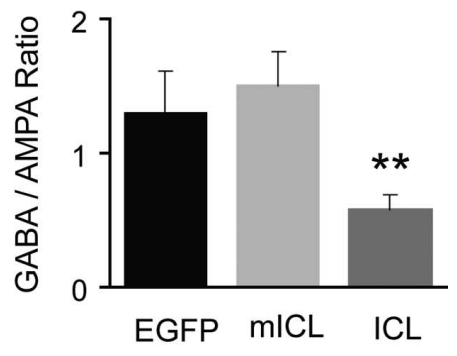

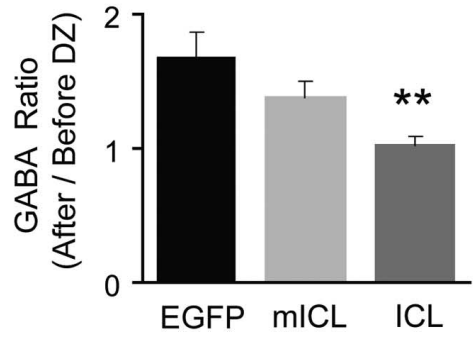

Figure 4. ICL expression alters inhibition to excitation ratio and benzodiazepam sensitivity without changing release probability or excitability. $A$, Recordings of IPSCS (average of 20 sweeps each) in response to paired stimuli $20-200 \mathrm{~ms}$ apart in control (top) and ICL-expressing neurons (bottom). Stimulus artifact was cut for clarity. $B$, Ratio of IPSC2/IPSC 1 in EGFP- and ICL-expressing neurons. The IPSC2/IPSC1 ratio in EGFP neurons was not significantly different from to ICL-expressing cells (MANOVA, $p>0.05$ ). EGFP: $n=13$. ICL: $n=11$ cells. Calibration: 20 pA, 20 ms. C, $\boldsymbol{D}$, ICL expression does not alter the neuronal intrinsic properties. C, Sample traces of evoked action potentials (top; calibration: $10 \mathrm{mV}, 20 \mathrm{~ms}$ ) in response to a step current pulse of $60 \mathrm{pA} / 200 \mathrm{~ms}$ (bottom; calibration: $50 \mathrm{pA}, 20 \mathrm{~ms}$ ) in an EGFP-expressing neuron (left) and an ICL-expressing neuron (right). D, Statistical plot of spike numbers in response to current pulses of increasing amplitudes. There is no significant difference between EGFP- (filled circle, $n=15$ ) and ICL-expression neurons (open circle, $n=15$ ) among different current-evoked spike numbers. $E, F$, ICL expression decreases the ratio of evoked GABA $A_{A}$-mediated synaptic currents to AMPAR-mediated synaptic currents. $E$, Representative recordings of evoked GABA $R$ - and AMPAR-mediated currents in EGFP-, mICL- and ICL-expressing neurons, respectively. Superimposition of synaptic currents in ICL-expressing neurons (gray) and EGFP neurons (black), normalized to the AMPAR-mediated synaptic response (right panel). Calibration: $20 \mathrm{pA}, 20 \mathrm{~ms}$. $\boldsymbol{F}$, The ratio of optic nerve stimulus-evoked $\mathrm{GABA}_{A} \mathrm{R}$-mediated synaptic currents to AMPAR-mediated synaptic currents in ICL-expressing neurons was significantly decreased compared with EGFP- or mICL-expressing neurons (EGFP: $1.35 \pm 0.32$; mICL: $1.50 \pm 0.26, \mathrm{ICL}: 0.56 \pm 0.12,{ }^{* *} p<0.05$ ). EGFP, $n=15 ; \mathrm{mICL}, n=7$; ICL, $n=12$ cells. G, $\boldsymbol{H}$, $G_{A B A} R$-mediated synaptic currents in ICL-expressing neurons are insensitive to diazepam. $G$, The amplitudes of evoked $G A B A_{A} R$-mediated synaptic currents in EGFP-expressing neurons were significantly increased after perfusion with diazepam (DZ, $2 \mu \mathrm{m}$ ) for $10 \mathrm{~min}$ (EGFP: from $32.67 \pm 2.57 \mathrm{pA}$ to $56.57 \pm 8.99 \mathrm{pA}$; ${ }^{*}<<0.01$ ), whereas $\mathrm{GABA}_{A} \mathrm{R}$-mediated synaptic currents in ICL-expressing neurons were insensitive to diazepam (ICL: from $23.06 \pm 3.01 \mathrm{pA}$ to $22.83 \pm 2.49 \mathrm{pA}$ ). Currents were completely blocked by picrotoxin in EGFP- or ICL-expressing neurons (PTX, bottom traces). Calibration: $20 \mathrm{pA}, 20 \mathrm{~ms}$. H, Quantification of benzodiazepine-sensitivity in EGFP-, mICL-, and ICL-expressing neurons as the ratio of the responses before and after diazepam (EGFP, $\left.1.67 \pm 0.20 \mathrm{pA}, n=12 ; \mathrm{mlCL}, 1.38 \pm 0.12 \mathrm{pA}, n=7 ; \mathrm{ICL}, 1.02 \pm 0.07 \mathrm{pA}, n=12 ;{ }^{*} p<0.01\right)$. 
A
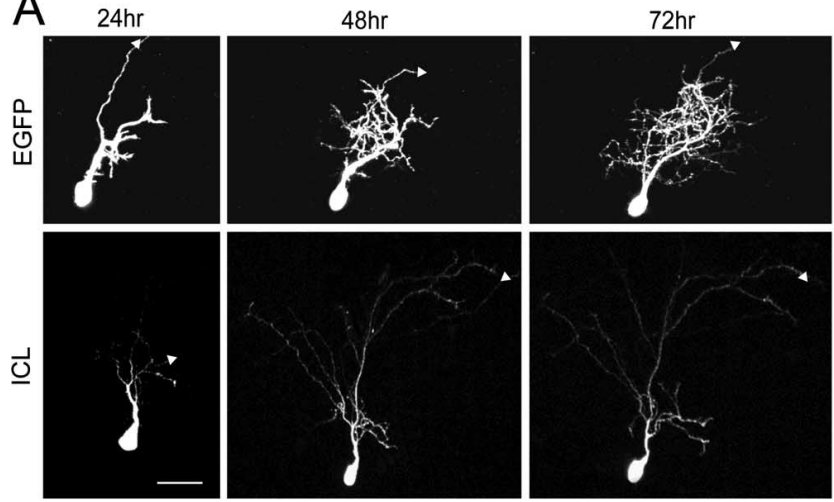

$72 \mathrm{hr}$ with measurements

B

- EGFP
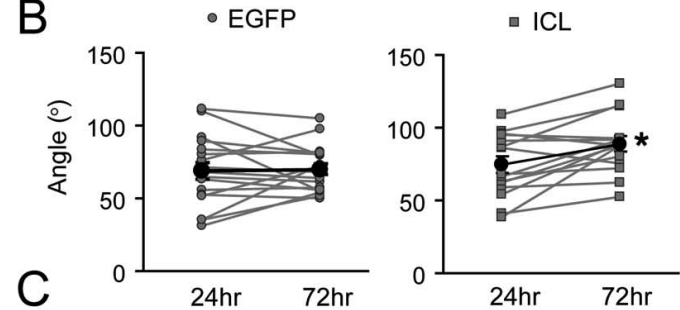

$\mathrm{D}$
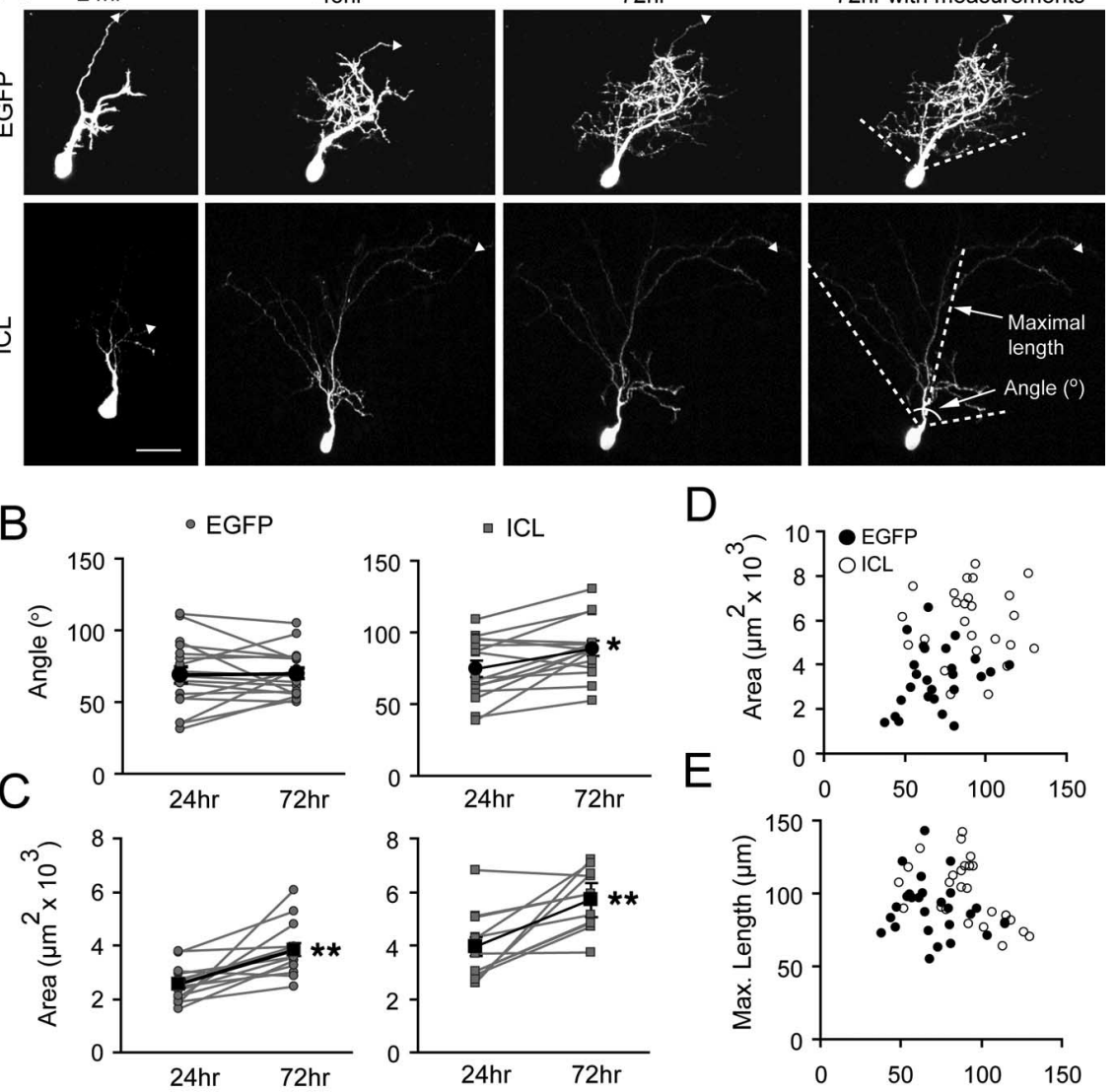

$\mathrm{F}$

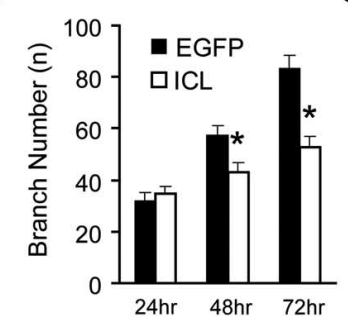

$G$

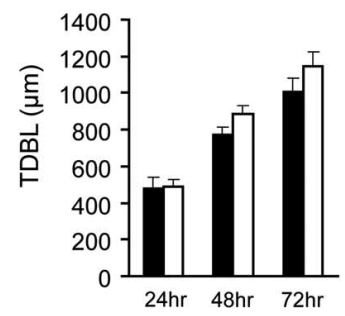

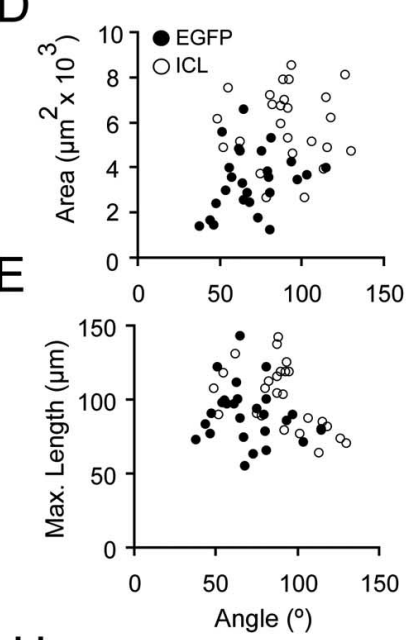

$\mathrm{H}$

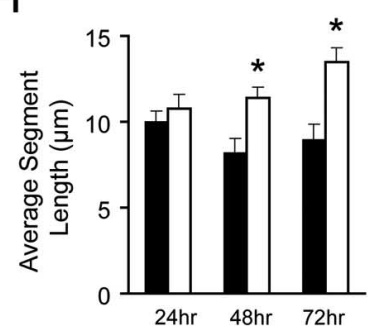

Figure 5. ICL expression affects dendritic arbor size and shape. $\boldsymbol{A}$, Representative tectal neurons expressing EGFP (top) or ICL (bottom) at 24, 48, and $72 \mathrm{~h}$. ICL-expressing neurons extend larger, sparsely branched arbors. Axons are indicated by arrowheads. Schematic measurement of angle, maximal length and area are shown overlaid on $72 \mathrm{~h}$ images of EGFP- and ICL-expressing neurons. Scale bar, $20 \mu \mathrm{m}$. $\boldsymbol{B}, \boldsymbol{C}$, ICL-expressing neurons have wider dendritic angles ( $\boldsymbol{B}$; right, ICL, $24 \mathrm{~h}: 74.29 \pm 5.64^{\circ} ; 72 \mathrm{~h}$ : $\left.88.83 \pm 5.22^{\circ}\right)$ and larger dendritic coverage over $48 \mathrm{~h}\left(\boldsymbol{C} ;\right.$ right, ICL, $24 \mathrm{~h}: 3957.77 \pm 333.57 \mu \mathrm{m}^{2} ; 72 \mathrm{~h}: 5704.48 \pm 286.66$ $\left.\mu \mathrm{m}^{2}{ }^{*}{ }^{*} p<0.05\right)$. EGFP-expressing neurons do not show significant difference of angels ( $\boldsymbol{B}$; left, EGFP, $24 \mathrm{~h}: 68.78 \pm 5.68^{\circ} ; 72 \mathrm{~h}$ : $69.8 \pm 3.78^{\circ}$ ) but increased areas over $48 \mathrm{~h}$ (C; left, EGFP, $\left.24 \mathrm{h:} 2555.77 \pm 159.27 \mu \mathrm{m}^{2} ; 72 \mathrm{h:} 3843.40 \pm 233.81 \mu \mathrm{m}^{2}\right)$. EGFP, $n=26 ; \mathrm{ICL}, n=25 . \boldsymbol{D}, \boldsymbol{E}$, Quantification of arbor features at $72 \mathrm{~h}$ : plots of dendritic tree angle versus estimated area $(\boldsymbol{D})$ and dendritic tree angle versus maximal length $(\boldsymbol{E})$. $\boldsymbol{F}-\boldsymbol{H}$, Plots of branch numbers $(\boldsymbol{F})$, total dendritic branch length (TDBL, $\mathbf{G})$, and average segment length $(\boldsymbol{H})$ for ICL- and EGFP-expressing neurons over $48 \mathrm{~h}$ of imaging. $\boldsymbol{F}$, ICL-expressing neurons fail to increase branch tip number over time compared with control neurons (EGFP, $24 \mathrm{~h}: 31.8 \pm 3.2 ; \mathrm{ICL}, 24 \mathrm{~h}: 34.5 \pm 2.9 ; \mathrm{EGFP}, 48 \mathrm{~h}, 57.3 \pm$ 3.7; ICL, 48 h, 43.2 $\pm 3.5 ; \mathrm{EGFP}, 72 \mathrm{~h}: 83.5 \pm 5.0 ; \mathrm{ICL}, 72 \mathrm{~h}: 52.9 \pm 4.1)$. G, TDBL values are not significantly different (EGFP, $24 \mathrm{~h}$ : $481.5 \pm 60.9 \mu \mathrm{m} ; \mathrm{ICL}, 24 \mathrm{~h}: 485.2 \pm 40.7 \mu \mathrm{m} ; \mathrm{EGFP}, 48 \mathrm{~h}, 772.6 \pm 42.5 \mu \mathrm{m} ; \mathrm{ICL}, 48 \mathrm{~h}, 885.3 \pm 42.6 \mu \mathrm{m} ; \mathrm{EGFP}, 72 \mathrm{~h}: 1010.6 \pm$ $69.9 \mu \mathrm{m} ; \mathrm{ICL}, 72 \mathrm{~h}: 1147.9 \pm 75.8 \mu \mathrm{m}) . \boldsymbol{H}$, ICL-expressing neurons significantly increase average segment lengths over $48 \mathrm{~h}$ (EGFP, $24 \mathrm{~h}: 9.99 \pm 0.66 \mu \mathrm{m} ; \mathrm{ICL}, 24 \mathrm{~h}: 10.76 \pm 0.83 \mu \mathrm{m}$; EGFP, $48 \mathrm{~h}, 8.22 \pm 0.83 \mu \mathrm{m} ; \mathrm{ICL}, 48 \mathrm{~h}, 11.38 \pm 0.65 \mu \mathrm{m}$; EGFP, $72 \mathrm{~h}$ : $8.95 \pm 0.94 \mu \mathrm{m} ; \mathrm{ICL}, 72 \mathrm{~h}: 13.48 \pm 0.84 \mu \mathrm{m})$. ICL, $n=9$ cells. EGFP, $n=9$ cells. ${ }^{*} p<0.05,{ }^{* *} p<0.01$.

arbor growth in vivo, by decreasing rates of net branch addition and decreasing branch density over time.

$\mathrm{GABA}_{\mathrm{A}} \mathrm{R}$-dependent regulation of dendritic branch dynamics Developing dendritic arbors continuously add and retract branches (Cline, 2001). Net growth of the arbor occurs because the relative rates of branch addition are greater than the rates of branch retraction (Rajan and Cline, 1998; Rajan et al., 1999; Wu and Cline, 2003; Hua and Smith, 2004). The failure of ICLexpressing neurons to increase branch tip numbers over time might result from decreased rates of branch additions or increased rates of branch retractions. To distinguish between these possibilities, we imaged EGFP- or ICL-expressing dendrites every 30 min over $2 \mathrm{~h}$, starting $24 \mathrm{~h}$ after electroporation (Fig. 6A). This imaging protocol allows us to detect differences in proportions of added, retracted and transient branches, whereas the daily imaging protocol allows us to document large-scale modifications in growth of the arbor. Because distal dendrites are more dynamic than primary dendrites over the $2 \mathrm{~h}$ imaging period (Cline, 2001; Hua and Smith, 2004), we focused our analysis on branch dynamics of secondary and higher order dendrites. We quantified the change in number and length of individual branch tips along the main dendritic branches. At the start of the imaging protocol, both the number (EGFP, $12.9 \pm 1.0$; ICL, $13.3 \pm 1.2$ ) and length (EGFP, $157.0 \pm$ $13.8 \mu \mathrm{m}$; ICL, $140.6 \pm 13.7 \mu \mathrm{m})$ of branches were similar in ICL-expressing neurons and controls (see also Fig. $5 F, G$ ). During the $2 \mathrm{~h}$ imaging period, the average length of individual branches in ICL-expressing neurons increased significantly more than in control neurons (Fig. 6B, left panel). Conversely, average branch tip number along the dendritic branches increased in control neurons but not in ICL-expressing neurons, so that control neurons increased their branch density over $2 \mathrm{~h}$, whereas ICL-expressing neurons significantly decreased their branch density (Fig. 6B, right panel). The results of the higher temporal resolution analysis of branch dynamics are consistent with the analysis of the overall arbor structure from daily imaging (decreased branch number and increased branch length) (Fig. 5).

To analyze branch dynamics, we classified branches as added, lost, transient, or maintained. As schematized in Figure 6, A and $C$, added branches were not present during the first image but were added at some point during the imaging protocol. Lost branches were present at the initial image and were retracted before the final image. Maintained branches were present throughout the imaging protocol. Transient branches were not present at the first image and were both added and retracted during the $2 \mathrm{~h}$ imaging period. Dendritic branches were color-coded according to their dynamic behaviors (Fig. 6A, C). EGFP- and ICL-expressing neurons have similar proportions of maintained branches, relative to the number of branches at the initial $(0 \mathrm{~min})$ time point (Fig. $6 D)$. ICL-expressing neurons have significantly fewer branch ad- 
ditions than controls (Fig. 6D), but branch retractions are not significantly different between the 2 groups. These findings suggest that $\mathrm{GABA}_{\mathrm{A}} \mathrm{R}$-dependent synaptic transmission affects dendritic arbor structure in vivo by regulating the rate of branch additions or the stabilization of newly added branches.

Experience-dependent dendritic growth requires $\mathrm{GABA}_{\mathrm{A}} \mathrm{R}$-dependent

\section{transmission}

The data presented above indicate that ICLexpressing neurons do not add branches at the same rates as in control neurons. Previous experiments have shown that enhanced visual stimulation increases rates of branch additions of optic tectal neurons in Xenopus (Sin et al., 2002; Haas et al., 2006). In particular, a protocol in which tadpoles are exposed to a $4 \mathrm{~h}$ period of darkness followed by a $4 \mathrm{~h}$ period of enhanced visual stimulation increases rates of branch additions and TDBL (Sin et al., 2002; Haas et al., 2006). We took advantage of this paradigm to test whether visual experience can stimulate branch addition in ICL-expressing neurons. Control neurons increase TDBL and branch number in response to $4 \mathrm{~h}$ of visual stimulation (Fig. $7 A-C$ ), as previously reported. In contrast, ICL-expressing neurons show similar rates of change for TDBL in the dark and after visual stimulation (Fig. $7 B$ ). Furthermore, the rate of increase in branch numbers in response to visual stimulation is significantly less in ICL-expressing neurons than controls (Fig. 7A,C). Branch density is significantly increased by visual activity in control neurons, whereas it is not modified by visual experience in ICL-expressing neurons, so that branch density in ICLexpressing neurons is significantly less than control neurons after enhanced visual experience (Fig. $7 D)$. These results indicate that the ICL expression blocks experience-dependent increases in dendritic arbor growth rates.

\section{Discussion}

Our work shows that expression of a peptide corresponding to the intracellular loop between TM 3 and TM 4 of the GABA $\mathrm{R} \gamma 2$ subunit effectively and specifically decreases $\mathrm{GABA}_{\mathrm{A}} \mathrm{R}$ dependent synaptic transmission in vivo. Furthermore, ICL expression by electroporation allows spatial and temporal control of inhibition of GABAergic synaptic transmission in the intact brain. Using this reagent, we showed that inhibitory $G_{A B A} R-$ mediated synaptic inputs affect dendritic arbor development and experience-dependent structural plasticity in vivo by regulating rates of branch additions.

Rationale for use of the ICL to block GABAergic transmission Studies examining the role of inhibitory $\mathrm{GABA}_{\mathrm{A}} \mathrm{R}$-mediated synaptic transmission in nervous system function have been hampered by the problems that pharmacological reagents that block
B

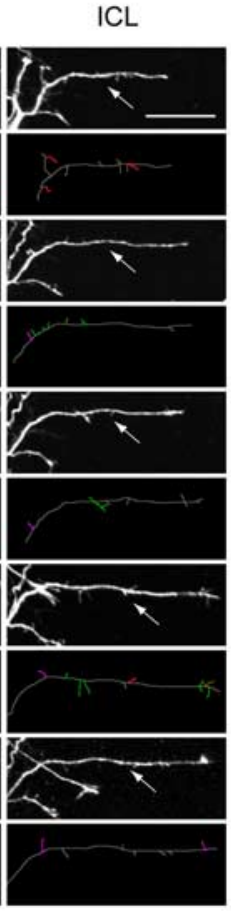

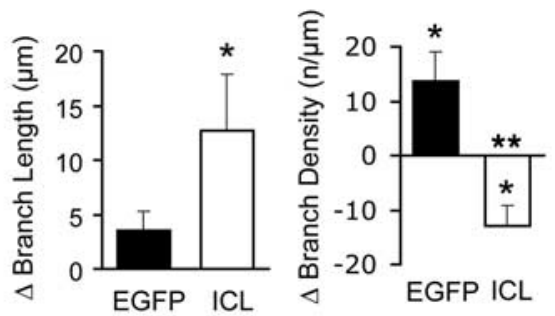
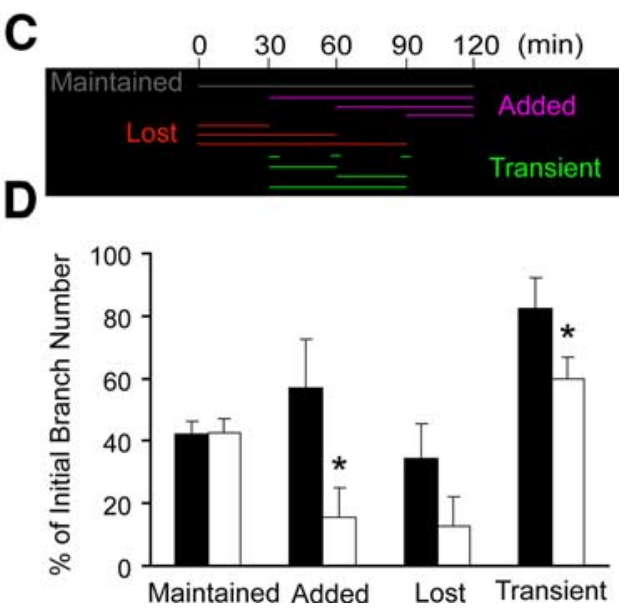

Figure 6. ICL expression regulates dendritic branch dynamics. $A$, Representative color-coded drawings of dendritic branches from EGFP- and ICL-expressing neurons imaged at $30 \mathrm{~min}$ intervals over $120 \mathrm{~min}$. The first two-photon image was collected $24 \mathrm{~h}$ code: gray, maintained branches in all images at 0-120 min; red, lost branches present at 0 min but not at 120 min; green,

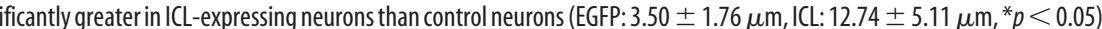

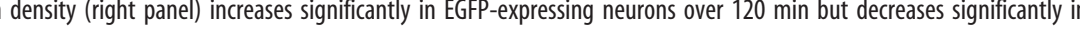
control and ICL-expressing neuronal dendrites is also significantly different ( $\left.{ }^{* *} p<0.01\right)$. C. Analysis of branch dynamics. Branches were categorized according to their dynamic behavior over the 120 min imaging period. The length of the lines corresponds to the time points (top) over which branches were observed and indicate branches that are maintained, lost, added or (Transient, EGFP: $82.57 \pm 9.80 \%$; ICL, 59.93\% $\pm 7.00 \%,{ }^{*} p<0.05$ ). Sum of added and lost branches, including transient branches shows that dendrites of ICL-expressing neurons add significantly fewer branches than controls (Additions: (Maintained, EGFP: $42.10 \pm 4.14 \%$, ICL: $42.63 \pm 4.41 \%$; Lost: EGFP, $34.35 \pm 11.13 \%$; ICL, $12.83 \pm 9.37 \%$ ). ICL, $n=18$ individual dendrites, six cells. EGFP, $n=17$ individual dendrites, six cells.

inhibition result in synchronous seizure-like activity and that many mice which are mutant in $\mathrm{GABA}_{\mathrm{A}} \mathrm{R}$ subunits or genes required for function of GABAergic transmission die perinatally (Günther et al., 1995; Essrich et al., 1998). Consequently, alternate strategies to perturb GABAergic synaptic transmission are required to probe the role of inhibition in the CNS development and function.

Endogenous synaptic $\mathrm{GABA}_{\mathrm{A}} \mathrm{R}$ are thought to be pentamers composed of two $\alpha$, two $\beta$, and one $\gamma$ (or one $\delta$ ) subunits (Lüscher and Keller, 2004; Rudolph and Möhler, 2004). Although $\alpha$ and $\beta$ subunits can form functional receptors, these are extrasynaptic and presence of the $\gamma$ subunit appears to be necessary and sufficient to cluster $\mathrm{GABA}_{\mathrm{A}} \mathrm{R}$ at synapses (Essrich et al., 1998; Schweizer et al., 2003; Lüscher and Keller, 2004; Christie et al., 2006). The intracellular loop between TM 3 and TM 4 of the $\gamma 2$ subunit is necessary for interaction with the scaffold protein gephyrin, which in turn is critical for clustering $\mathrm{GABA}_{\mathrm{A}} \mathrm{R}$ at synapses (Alldred et al., 2005; Christie et al., 2006), although gephyrin does not appear to interact directly with the $\gamma 2$ subunit. As- 
A

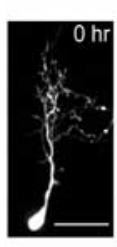

$$
\text { EGFP }
$$
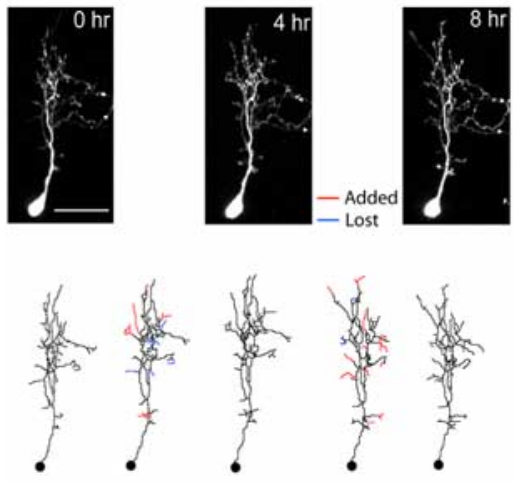

ICL
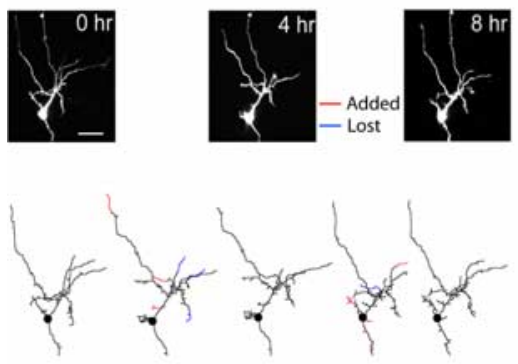

B

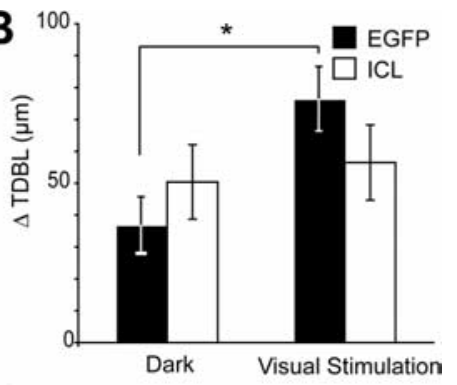

C

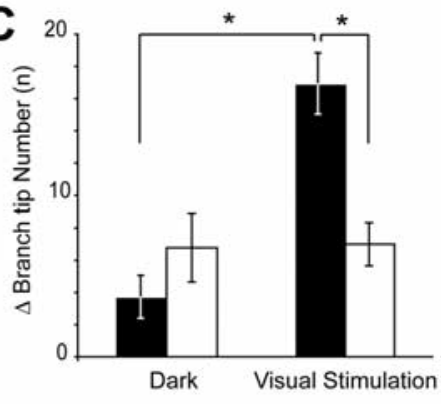

D

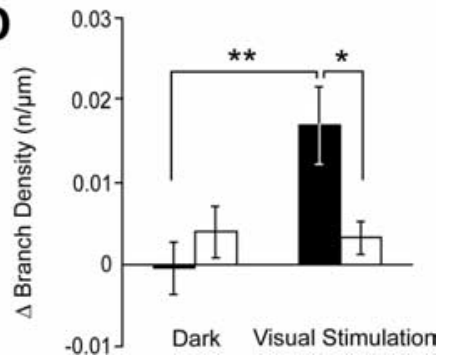

Figure 7. Experience-dependent structural plasticity requires $G_{A B A} R$-dependent synaptic transmission. $\boldsymbol{A}$, Images and drawings of representative tectal neurons expressing EGFP (top) or ICL (bottom) are shown at 0,4 , and $8 \mathrm{~h}$, respectively. Color-coded drawings of the neurons are shown between 0 and $4 \mathrm{~h}$ or 4 and $8 \mathrm{~h}$, in which added branches are shown in red and retracted branches are shown in blue. The black circle marks the soma. Axons are indicated by arrowheads in the images and they are omitted in the drawings. Scale bar, $20 \mu \mathrm{m}$. $\boldsymbol{B}-\boldsymbol{D}$, Change in $(\boldsymbol{B})$ total dendritic branch length, $(\boldsymbol{C})$ branch tip number and $(\boldsymbol{D})$ branch density over $4 \mathrm{~h}$ in the dark and with visual stimulation for control and ICL-expressing neurons. $\boldsymbol{B}, \boldsymbol{C}$, Control neurons significantly increase growth rate assessed by TDBL (Dark, 36.69 $\pm 8.91 \mu \mathrm{m}$; Visual Stimulation, $76.29 \pm 10.10 \mu \mathrm{m} ;{ }^{*} p<0.05$ ) and rate of branch additions upon visual stimulation (Dark, $3.70 \pm 1.33$; Visual Stimulation, $16.90 \pm 1.91$; ${ }^{*} p<0.05$ ). ICLexpressing neurons do not increase growth rate (TDBL or branch tip number) with visual stimulation (TDBL: Dark, 50.42 \pm 11.67 $\mu \mathrm{m}$; Visual Stimulation, $56.50 \pm 11.78 \mu \mathrm{m}$; branch number: Dark, $6.78 \pm 2.13$; Visual Stimulation, $7.00 \pm 1.34)$. ICLexpressing neurons have added significantly fewer branch tips than controls after visual stimulation $\left({ }^{*} p<0.05\right)$. D, Control neurons increase branch density to a significantly greater extent with visual stimulation compared with dark, but ICL-expressing neurons show no effect of visual stimulation on branch density (EGFP: Dark, $-0.0004 \pm 0.0031$ branch no./micrometer, Visual Stimulation, $0.0170 \pm 0.0046$ branch no./micrometer; ICL: Dark, $0.0040 \pm 0.0030$ branch no./micrometer, Visual Stimulation, $0.0032 \pm 0.0019$ branch no./micrometer; ${ }^{* *} p<0.01$; $\left.{ }^{*} p<0.05\right)$. ICL, $n=10$ cells. EGFP, $n=11$ cells.

sociation of the $\gamma 2$ subunit and gephyrin may also be required for $\mathrm{GABA}_{\mathrm{A}} \mathrm{R}$ internalization (Essrich et al., 1998; Schweizer et al., 2003; Alldred et al., 2005), suggesting that the interaction between gephyrin and $\gamma 2$ subunit-containing $\mathrm{GABA}_{\mathrm{A}} \mathrm{R}$ controls the number of resident $\mathrm{GABA}_{\mathrm{A}} \mathrm{R}$ at synaptic sites by regulating both the clustering of receptors in synapses and their internalization. The decrease in GABAergic transmission we see with ICL expression is consistent with the idea that interaction between the $\gamma 2$ subunit and gephyrin is required to maintain $\gamma 2$ subunit containing $\mathrm{GABA}_{\mathrm{A}} \mathrm{R}$ at synapses.

The $\gamma 2$ subunit of the $\mathrm{GABA}_{\mathrm{A}} \mathrm{R}$ is highly conserved between Xenopus and mammalian species. Antibody labeling for $\gamma 2$ protein indicates that midbrain neurons in Xenopus express $\gamma 2$ subunits, which are located in neuronal cell bodies and distributed in a punctate pattern in dendrites. The dendritic distribution of EGFP-ICL in puncta apposed to VGAT positive puncta suggests that ICL accumulates at GABAergic postsynaptic sites, consistent with previous reports in cultured neurons (Essrich et al., 1998; Kittler et al., 2000; Meier and Grantyn, 2004) and in brain sections (Crestani et al., 1999; Schweizer et al., 2003). The distribution of EGFP-ICL indicates that ICL is situated where it can compete with endogenous $\gamma 2$ subunits for binding sites with postsynaptic scaffold proteins (Kittler et al., 2000), which may in turn decrease synaptic localization of $\gamma 2$ or $\alpha 2$-containing $\mathrm{GABA}_{\mathrm{A}} \mathrm{R}$ (Schweizer et al., 2003). $G_{A B A_{A}} R$ are found to recycle between synaptic sites and intracellular compartments, and mechanisms controlling receptor trafficking regulate receptor clusters and synaptic efficacy (Kittler and Moss, 2003).

\section{ICL expression decreases inhibitory synaptic input}

Neurons have tight control over the balance of excitation to inhibition (Liu, 2004). We find that about one third of ICL-expressing neurons have no detectable mIPSCs indicating that ICL expression blocks GABAergic inputs in transfected neurons. In the remaining two thirds of the neurons, ICL expression significantly decreased mIPSC frequency but not AMPAR-mediated mEPSC frequency. The decrease in MIPSC frequency likely represents a decrease in inhibitory synaptic inputs on ICL-expressing neurons, rather than a decrease in presynaptic function, based on our observation of no change in synaptic release probability. The decrease in the ratio of optic nerve evoked GABAergic synaptic responses relative to glutamatergic synaptic transmission, further supports the conclusion that ICL expression results in decreased inhibitory input and a specific shift in the ratio of excitatory synaptic inputs to inhibitory synaptic inputs. Benzodiazepine binding to $\mathrm{GABA}_{\mathrm{A}} \mathrm{R}$ occurs at the interface of the $\gamma 2$ and $\alpha$ subunits (Günther et al., 1995; Sigel, 2002) and diazepam-mediated enhancement of GABAergic responses are diagnostic of the presence of the $\gamma 2$ subunit. We find that diazepam treatment increases the magnitude of evoked GABAergic synaptic transmission in optic tectal neurons as in other systems (Günther et al., 1995; Crestani et al., 1999; Wallace et al., 2001; Sigel, 2002). ICL-expressing tectal neurons do not show diazepam-mediated increases of GABAergic responses, consistent with the idea that residual synaptic $\mathrm{GABA}_{\mathrm{A}} \mathrm{R}$ in ICLexpressing neurons lack the $\gamma 2$ subunit, and that the remaining GABAergic synaptic transmission might be mediated by $\gamma 2$ subunit-lacking receptors (Essrich et al., 1998), possibly $\gamma 3$ subunit-containing receptors (Baer et al., 1999). These data indicate that ICL expression decreases synaptic transmission mediated by $\gamma 2$ subunit-containing $\mathrm{GABA}_{\mathrm{A}} \mathrm{R}$, consistent with previous studies showing that the $\gamma 2$ subunit is required for clustering of major $\mathrm{GABA}_{\mathrm{A}}$ receptor subtypes with gephyrin at postsynaptic sites (Essrich et al., 1998; Schweizer et al., 2003; Alldred et al., 
2005). Therefore, ICL expression provides a means to assess the requirement for $\mathrm{GABA}_{\mathrm{A}} \mathrm{R}$-mediated synaptic transmission on the development of dendritic arbor structure.

\section{GABAergic synaptic transmission is required for dendritic arbor growth}

Using this tool, we probed the role of inhibitory $\mathrm{GABA}_{\mathrm{A}} \mathrm{R}$ dependent synaptic transmission on dendritic arbor development and structural plasticity, by visualizing the cellautonomous effects of ICL expression in single tectal neurons in the intact $X$. laevis, at a developmental time when GABAergic transmission is inhibitory (Akerman and Cline, 2006). During dendritic arbor development, when branches are continuously added and retracted, the stabilization of a fraction of newly added branches is required for the net elaboration of the arbor (Cline, 2001; Cohen-Cory, 2002; Hua and Smith, 2004). The requirement for glutamatergic synaptic transmission in dendritic arbor elaboration was initially shown with pharmacological manipulations (Kalb, 1994; Rajan and Cline, 1998; Rajan et al., 1999) and subsequently by expression of receptor subunits or peptides corresponding to the cytoplasmic tail of glutamate receptor subunits (Inglis et al., 2002; Haas et al., 2006). Preventing maturation of glutamatergic synapses prevented normal dendritic arbor development and experience-dependent structural plasticity by blocking the stabilization of dynamic dendritic branches (Haas et al., 2006; Cline and Haas, 2008).

In contrast, the role of inhibition in controlling dendritic arbor elaboration has been more challenging to establish. In a clever set of experiments, unilateral cochlear ablation and the resulting deafferentiation of the lateral superior olive (LSO) in the gerbil auditory system decreases glycinergic inputs to the contralateral LSO neurons (Sanes and Chokshi, 1992). This in turn increased the tangential extent of the LSO neuronal dendritic arbors in the tonotopic map (Sanes and Chokshi, 1992; Sanes et al., 1992). These studies suggested a role for inhibitory inputs in controlling dendritic arbor growth. Similarly, we find that blocking inhibitory GABAergic inputs results in dendritic arbors that spread over a larger tangential extent than control neurons, although the arbors are more sparsely branched than controls. Analysis of branch dynamics from images collected at shorter interval indicates that decreased inhibitory GABAergic transmission decreases rates of dendritic branch additions. A decreased rate of branch additions likely accounts for arbors that are more sparsely branched.

\section{Inhibition is required for experience-dependent structural plasticity}

The Xenopus retinotectal system demonstrates rapid experiencedependent structural plasticity that can be detected as in increase in the rate of dendritic arbor growth rate with a relatively brief exposure of $4 \mathrm{~h}$ to enhanced visual stimulation (Sin et al., 2002). The visual experience-dependent structural plasticity requires AMPAR- and NMDAR-mediated synaptic transmission (Sin et al., 2002; Haas et al., 2006; Ewald et al., 2008) as well as signaling processes involving insulin receptors (Chiu et al., 2008), RhoA GTPases (Sin et al., 2002) and dendritic protein synthesis (Bestman and Cline, 2008). The structural plasticity is accompanied by increased synaptogenesis and increased synapse strength (Aizenman and Cline, 2007). At early stages of neuronal development, excitatory GABAergic signaling cooperates with NMDAR signaling to promote maturation of AMPAR-mediated synaptic transmission (Akerman and Cline, 2006). It also affects morphological maturation in cortical neurons (Cancedda et al., 2007) and in retinal ganglion cells (Leitch et al., 2005) with the result that retinal receptive field sizes are altered. Here we show that when GABAergic transmission is hyperpolarizing (Akerman and Cline, 2006), GABA $\mathrm{A}_{\mathrm{A}} \mathrm{R}$-mediated synaptic transmission is critical for visual experience-dependent structure plasticity. ICL expression prevents the increase in total dendritic branch length and branch tip numbers that normally occur with $4 \mathrm{~h}$ enhanced visual stimulation. The data indicate that $\mathrm{GABA}_{\mathrm{A}} \mathrm{R}$-dependent synaptic inputs have a pivotal impact on experience-dependent dendritic structural plasticity and that this likely occurs through cellautonomous mechanisms rather than by changes in circuit wide activity. The observation that ICL expression decreases GABAergic synaptic inputs, whereas leaving excitatory synaptic inputs largely unchanged raises the possibility that the ratio of inhibition to excitation may be a key determinant of dendritic arbor structure. Expressing the peptide corresponding to AMPAR cytoplasmic tails prevents glutamatergic synapse maturation (Haas et al., 2006) but does not affect mIPSC amplitude or frequency (W. H. Shen and H. T. Cline, unpublished observations), suggesting that the ratio of excitation to inhibition is decreased. It is striking that the AMPAR c-tail expressing neurons and the ICL-expressing neurons have similar deficits in dendritic arbor growth and experience-dependent plasticity, although excitation/inhibition changes in opposite directions. Evidence that the excitation ratio is tightly regulated (Liu, 2004) together with our data suggests that deviations from a mid-range of excitation/inhibition in either direction affects neuronal structural development, and likely circuit development and function.

\section{References}

Aizenman CD, Cline HT (2007) Enhanced visual activity in vivo forms nascent synapses in the developing retinotectal projection. J Neurophysiol 97:2949-2957.

Akerman CJ, Cline HT (2006) Depolarizing GABAergic conductances regulate the balance of excitation to inhibition in the developing retinotectal circuit in vivo. J Neurosci 26:5117-5130.

Alldred MJ, Mulder-Rosi J, Lingenfelter SE, Chen G, Lüscher B (2005) Distinct $\gamma 2$ subunit domains mediate clustering and synaptic function of postsynaptic $\mathrm{GABA}_{\mathrm{A}}$ receptors and gephyrin. J Neurosci 25:594-603.

Baer K, Essrich C, Benson JA, Benke D, Bluethmann H, Fritschy JM, Lüscher B (1999) Postsynaptic clustering of gamma-aminobutyric acid type A receptors by the gamma3 subunit in vivo. Proc Natl Acad Sci U S A 96:12860-12865.

Baer K, Essrich C, Balsiger S, Wick MJ, Harris RA, Fritschy JM, Lüscher B (2000) Rescue of gamma2 subunit-deficient mice by transgenic overexpression of the GABAA receptor gamma2S or gamma2L subunit isoforms. Eur J Neurosci 12:2639-2643.

Barbin G, Pollard H, Gaïarsa JL, Ben-Ari Y (1993) Involvement of GABAA receptors in the outgrowth of cultured hippocampal neurons. Neurosci Lett 152:150-154.

Ben-Ari Y (2002) Excitatory actions of gaba during development: the nature of the nurture. Nat Rev Neurosci 3:728-739.

Ben-Ari Y, Cherubini E, Corradetti R, Gaiarsa JL (1989) Giant synaptic potentials in immature rat CA3 hippocampal neurones. J Physiol 416:303-325.

Bestman JE, Cline HT (2008) The RNA binding protein CPEB regulates dendrite morphogenesis and neuronal circuit assembly in vivo. Proc Natl Acad Sci U S A 105:20494-20499.

Bestman JE, Ewald RC, Chiu SL, Cline HT (2006) In vivo single-cell electroporation for transfer of DNA and macromolecules. Nat Protoc 1:1267-1272.

Borba JM, Araújo MS, Picanço-Diniz CW, Manhães-de-Castro R, Guedes RC (2000) Permanent and transitory morphometric changes of NADPHdiaphorase-containing neurons in the rat visual cortex after early malnutrition. Brain Res Bull 53:193-201.

Cancedda L, Fiumelli H, Chen K, Poo MM (2007) Excitatory GABA action is essential for morphological maturation of cortical neurons in vivo. J Neurosci 27:5224-5235. 
Chen G, Trombley PQ, van den Pol AN (1996) Excitatory actions of GABA in developing rat hypothalamic neurones. J Physiol 494:451-464.

Chiu SL, Chen CM, Cline HT (2008) Insulin receptor signaling regulates synapse number, dendritic plasticity, and circuit function in vivo. Neuron 58:708-719.

Christie SB, Li RW, Miralles CP, Yang BY, De Blas AL (2006) Clustered and non-clustered GABAA receptors in cultured hippocampal neurons. Mol Cell Neurosci 31:1-14.

Cline HT (2001) Dendritic arbor development and synaptogenesis. Curr Opin Neurobiol 11:118-126.

Cline H, Haas K (2008) The regulation of dendritic arbor development and plasticity by glutamatergic synaptic input: a review of the synaptotrophic hypothesis. J Physiol 586:1509-1517.

Cohen-Cory S (2002) The developing synapse: construction and modulation of synaptic structures and circuits. Science 298:770-776.

Coleman LA, Friedlander MJ (2002) Postnatal dendritic development of Y-like geniculocortical relay neurons. Int J Dev Neurosci 20:137-159.

Crestani F, Lorez M, Baer K, Essrich C, Benke D, Laurent JP, Belzung C, Fritschy JM, Lüscher B, Mohler H (1999) Decreased GABAA-receptor clustering results in enhanced anxiety and a bias for threat cues. Nat Neurosci 2:833-839.

Essrich C, Lorez M, Benson JA, Fritschy JM, Lüscher B (1998) Postsynaptic clustering of major GABAA receptor subtypes requires the gamma 2 subunit and gephyrin. Nat Neurosci 1:563-571.

Ewald RC, Van Keuren-Jensen KR, Aizenman CD, Cline HT (2008) Roles of NR2A and NR2B in the development of dendritic arbor morphology in vivo. J Neurosci 28:850-861.

Fritschy JM, Schweizer C, Brünig I, Lüscher B (2003) Pre- and post-synaptic mechanisms regulating the clustering of type A gamma-aminobutyric acid receptors (GABAA receptors). Biochem Soc Trans 31:889-892.

Gillespie DC, Kim G, Kandler K (2005) Inhibitory synapses in the developing auditory system are glutamatergic. Nat Neurosci 8:332-338.

Günther U, Benson J, Benke D, Fritschy JM, Reyes G, Knoflach F, Crestani F, Aguzzi A, Arigoni M, Lang Y (1995) Benzodiazepine-insensitive mice generated by targeted disruption of the gamma 2 subunit gene of gammaaminobutyric acid type A receptors. Proc Natl Acad Sci USA 92:7749-7753.

Gutiérrez A, Khan ZU, De Blas AL (1994) Immunocytochemical localization of gamma 2 short and gamma 2 long subunits of the GABAA receptor in the rat brain. J Neurosci 14:7168-7179.

Haas K, Jensen K, Sin WC, Foa L, Cline HT (2002) Targeted electroporation in Xenopus tadpoles in vivo-from single cells to the entire brain. Differentiation 70:148-154.

Haas K, Li J, Cline HT (2006) AMPA receptors regulate experiencedependent dendritic arbor growth in vivo. Proc Natl Acad Sci U S A 103:12127-12131.

Hua JY, Smith SJ (2004) Neural activity and the dynamics of central nervous system development. Nat Neurosci 7:327-332.

Inglis FM, Crockett R, Korada S, Abraham WC, Hollmann M, Kalb RG (2002) The AMPA receptor subunit GluR1 regulates dendritic architecture of motor neurons. J Neurosci 22:8042-8051.

Kalb RG (1994) Regulation of motor neuron dendrite growth by NMDA receptor activation. Development 120:3063-3071.

Kittler JT, Moss SJ (2003) Modulation of GABAA receptor activity by phosphorylation and receptor trafficking: implications for the efficacy of synaptic inhibition. Curr Opin Neurobiol 13:341-347.

Kittler JT, Wang J, Connolly CN, Vicini S, Smart TG, Moss SJ (2000) Analysis of GABAA receptor assembly in mammalian cell lines and hippocampal neurons using gamma 2 subunit green fluorescent protein chimeras. Mol Cell Neurosci 16:440-452.

Leitch E, Coaker J, Young C, Mehta V, Sernagor E (2005) GABA type-A activity controls its own developmental polarity switch in the maturing retina. J Neurosci 25:4801-4805.

Liu G (2004) Local structural balance and functional interaction of excitatory and inhibitory synapses in hippocampal dendrites. Nat Neurosci 7:373-379.

Lüscher B, Keller CA (2004) Regulation of GABAA receptor trafficking, channel activity, and functional plasticity of inhibitory synapses. Pharmacol Ther 102:195-221.

Maric D, Liu QY, Maric I, Chaudry S, Chang YH, Smith SV, Sieghart W, Fritschy JM, Barker JL (2001) GABA expression dominates neuronal lineage progression in the embryonic rat neocortex and facilitates neurite outgrowth via $\mathrm{GABA}_{\mathrm{A}}$ autoreceptor/Cl- channels. J Neurosci 21:2343-2360.

Martin KA, Whitteridge D (1984) The relationship of receptive field properties to the dendritic shape of neurones in the cat striate cortex. J Physiol 356:291-302.

Meier J, Grantyn R (2004) Preferential accumulation of GABAA receptor gamma $2 \mathrm{~L}$, not gamma $2 \mathrm{~S}$, cytoplasmic loops at rat spinal cord inhibitory synapses. J Physiol 559:355-365.

Mody I, Pearce RA (2004) Diversity of inhibitory neurotransmission through GABA(A) receptors. Trends Neurosci 27:569-575.

Rajan I, Cline HT (1998) Glutamate receptor activity is required for normal development of tectal cell dendrites in vivo. J Neurosci 18:7836-7846.

Rajan I, Witte S, Cline HT (1999) NMDA receptor activity stabilizes presynaptic retinotectal axons and postsynaptic optic tectal cell dendrites in vivo. J Neurobiol 38:357-368.

Rudolph U, Möhler H (2004) Analysis of GABAA receptor function and dissection of the pharmacology of benzodiazepines and general anesthetics through mouse genetics. Annu Rev Pharmacol Toxicol 44:475-498.

Ruthazer ES, Li J, Cline HT (2006) Stabilization of axon branch dynamics by synaptic maturation. J Neurosci 26:3594-3603.

Sanes DH, Chokshi P (1992) Glycinergic transmission influences the development of dendrite shape. Neuroreport 3:323-326.

Sanes DH, Hafidi A (1996) Glycinergic transmission regulates dendrite size in organotypic culture. J Neurobiol 31:503-511.

Sanes DH, Markowitz S, Bernstein J, Wardlow J (1992) The influence of inhibitory afferents on the development of postsynaptic dendritic arbors. J Comp Neurol 321:637-644.

Schweizer C, Balsiger S, Bluethmann H, Mansuy IM, Fritschy JM, Mohler H, Lüscher B (2003) The gamma 2 subunit of GABA(A) receptors is required for maintenance of receptors at mature synapses. Mol Cell Neurosci 24:442-450.

Shapiro LA, Korn MJ, Ribak CE (2005) Newly generated dentate granule cells from epileptic rats exhibit elongated hilar basal dendrites that align along GFAP-immunolabeled processes. Neuroscience 136:823-831.

Sigel E (2002) Mapping of the benzodiazepine recognition site on GABA(A) receptors. Curr Top Med Chem 2:833-839.

Sin WC, Haas K, Ruthazer ES, Cline HT (2002) Dendrite growth increased by visual activity requires NMDA receptor and Rho GTPases. Nature 419:475-480.

Smear MC, Tao HW, Staub W, Orger MB, Gosse NJ, Liu Y, Takahashi K, Poo MM, Baier H (2007) Vesicular glutamate transport at a central synapse limits the acuity of visual perception in zebrafish. Neuron 53:65-77.

Tapia JC, Mentis GZ, Navarrete R, Nualart F, Figueroa E, Sánchez A, Aguayo LG (2001) Early expression of glycine and GABA(A) receptors in developing spinal cord neurons. Effects on neurite outgrowth. Neuroscience 108:493-506.

van Rijnsoever C, Sidler C, Fritschy JM (2005) Internalized GABA-receptor subunits are transferred to an intracellular pool associated with the postsynaptic density. Eur J Neurosci 21:327-338.

Wallace RH, Marini C, Petrou S, Harkin LA, Bowser DN, Panchal RG, Williams DA, Sutherland GR, Mulley JC, Scheffer IE, Berkovic SF (2001) Mutant GABA(A) receptor gamma2-subunit in childhood absence epilepsy and febrile seizures. Nat Genet 28:49-52.

Wayman GA, Impey S, Marks D, Saneyoshi T, Grant WF, Derkach V, Soderling TR (2006) Activity-dependent dendritic arborization mediated by CaM-kinase I activation and enhanced CREB-dependent transcription of Wnt-2. Neuron 50:897-909.

Wong RO, Ghosh A (2002) Activity-dependent regulation of dendritic growth and patterning. Nat Rev Neurosci 3:803-812.

Wu GY, Cline HT (2003) Time-lapse in vivo imaging of the morphological development of Xenopus optic tectal interneurons. J Comp Neurol 459: 392-406. 